A Platinum Open Access Journal

for Organic Chemistry

Paper

Free to Authors and Readers

DOAJ Seal

Arkivoc 2021, part iv, 280-296

\title{
Synthesis of modified miuraenamides - the Ugi approach
}

\author{
Sarah Kappler and Uli Kazmaier* \\ Organic Chemistry, Saarland University, Campus C4.2, 66123 Saarbrücken, Germany \\ Email: u.kazmaier@mx.uni-saarland.de
}

Dedication to Prof. Horst Kunz on the occasion of his $80^{\text {th }}$ birthday

Received 02-26-2020

Accepted 02-12-2021

Published on line $02-18-2021$

\section{Abstract}

Miuraenamides, a group of marine cyclodepsipeptides, closely related to jasplakinolide and geodiamolide are found to accelerate nucleation and polymerization of actin, and therefore interfere with cell division processes, at concentrations in the low nanomolar range. For SAR studies derivatives are synthesized via Ugi reaction, which provides the complete tripeptide fragment in only one step. While a wide range of modifications are possible at the $C$-terminus of the peptide, variations at the central position are not tolerated. Neither modifications in the polyketide.
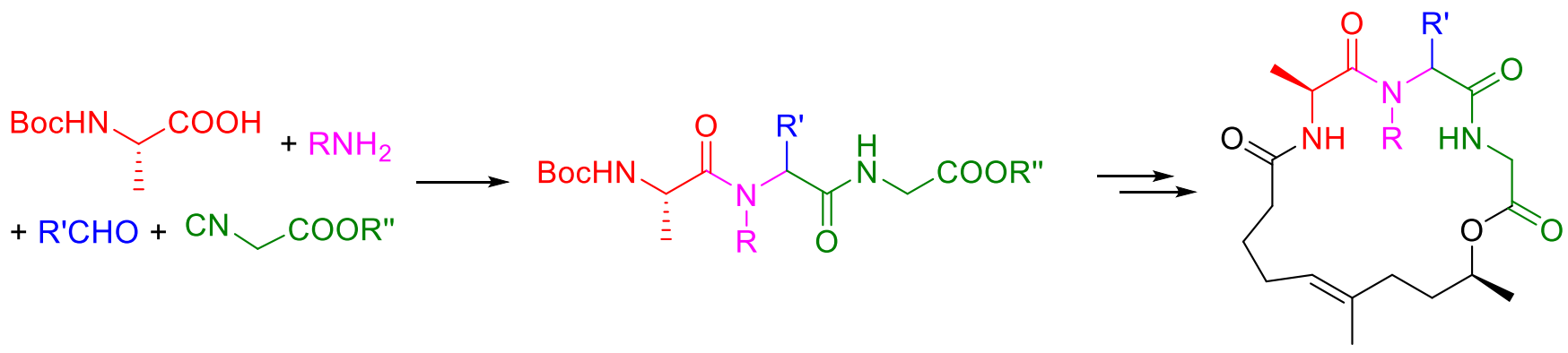

Keywords: Actin, cyclodepsipeptides, multicomponent reactions, natural products, polyketides, Ugi reactions 


\section{Introduction}

Myxobacteria, highly interesting Gram-negative $\delta$-proteobacteria, were initially considered as terrestrial microorganisms ${ }^{1,2}$ but in the meanwhile a lot of marine representatives have been discovered during the last years. $^{3,4}$ Their rich secondary metabolism makes them one of the best natural product producers, ${ }^{5,6}$ and many of their metabolites are interesting candidates for drug development. ${ }^{7}$

In 2006, Lizuka et al. isolated a novel lightly halophilic myxobacterium, Paraliomyxa miuraensis, from a soil sample at the coast of Japan. ${ }^{8}$ Investigating the secondary metabolites produced by this species resulted in the isolation of miuraenamides $A$ and $B^{8}$ and two years later also of the derivatives C-F (Figure 1)..$^{9}$ The miuraenamides are structurally closely related to a range of other cyclodepsipetides, such as the chondramides, ${ }^{10-12}$ also produced by myxobacteria or the geodiamolides, ${ }^{13}$ seragamides $^{14}$ or jasplakinolide. ${ }^{15,16}$ All these natural products have been isolated from sponges, but probably they are not produced by them but might also be secondary metabolites from bacteria living in them. ${ }^{9}$

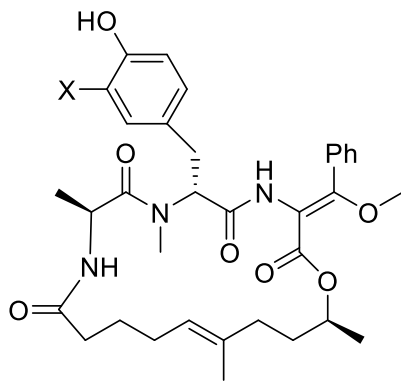

Miuraenamide $\mathrm{A} \quad \mathrm{X}=\mathrm{Br}$

B $X=1$

C $\mathrm{X}=\mathrm{Cl}$

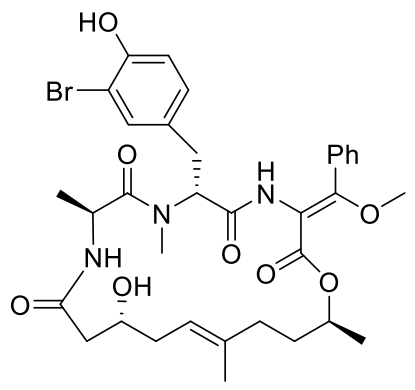

Miuraenamide F

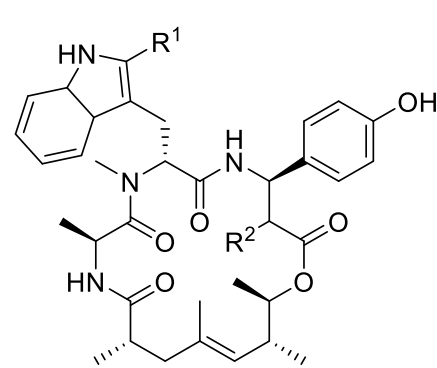

Chondramide $A: \mathrm{R}^{1}=\mathrm{H}, \mathrm{R}^{2}=\mathrm{OMe}$ B: $\mathrm{R}^{1}=\mathrm{Cl}, \mathrm{R}^{2}=\mathrm{OMe}$ C: $\mathrm{R}^{1}=\mathrm{H}, \mathrm{R}^{2}=\mathrm{H}$ D: $\mathrm{R}^{1}=\mathrm{Cl}, \mathrm{R}^{2}=\mathrm{H}$

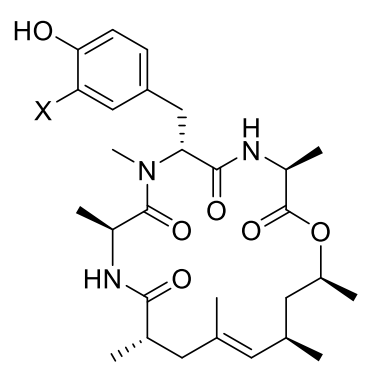

Geodiamolide $A: X=1$

B: $X=B r$

C: $X=\mathrm{Cl}$

Figure 1. Natural occurring cyclodepsipeptides.

Like the other cyclodepsipeptides the miuraenamides can be divided into two major building blocks: a tripeptide containing a halogenated tyrosine in the central position and a polyketide fragment. The derivatives mainly differ in the halogenation pattern of the tyrosine and the $C$-terminal unusual amino acid containing a methoxyacrylate ( $E$ or $Z$ ) motif. In miuraenamide $F$ an additional hydroxylated polyketide is incorporated. Differences in this hydroxycarboxylic acid are also found, e.g. in the chondramides or geodiamolides, not only in the position of the double bond and the substitution pattern, but also the chain length.

By far most investigations concerning the biological activity and the mode of action were carried out with jasplakinolide (jaspamide), which shows high cytotoxicity towards a range of leukemia, breast and prostate cancer cell lines. ${ }^{17}$ Jasplakinolide was found to initiate actin polymerization and stabilizes already formed actin microfilaments, which causes significant morphological changes in the cell. ${ }^{18,19}$ The same effects were also observed for the geodiamolides, ${ }^{17}$ chondramides ${ }^{20,21}$ and the miuraenamides. ${ }^{22-24}$ While the other natural products contain six to seven stereogenic centres, the miuraenamides A-C contain only three asymmetric Catoms (and one stereoisomeric double bond). Therefore, the miuraenamides might be ideal candidates for the development of potential anti-tumor drugs. 


\section{Results and Discussion}

Concerning our ongoing interest into the syntheses of biological active natural products ${ }^{25-30}$ we also focused on the synthesis of chondramide derivatives 31,32 and we developed a straightforward protocol towards the miuraenamides ${ }^{33}$ based on a late stage modification approach. ${ }^{34}$ This concept allowed the synthesis of a small library of miuraenamide derivatives via aldol reaction at the $C$-terminal position of a glycine containing cyclodepsipeptide (Scheme 1). ${ }^{35}$ SAR studies clearly indicated that the $C$-terminal amino acid can be varied in a wide range without significant effect on the biological activity of the derivatives. Obviously the unusual unsaturated amino acid is not required for the anti-cancer activity, a derivative without a side chain was found to be even more active towards several cell lines than the natural products. Therefore, the already rather simple structure could even be further simplified, what forced us to investigate also modifications at the central amino acid and the polyketide fragment.

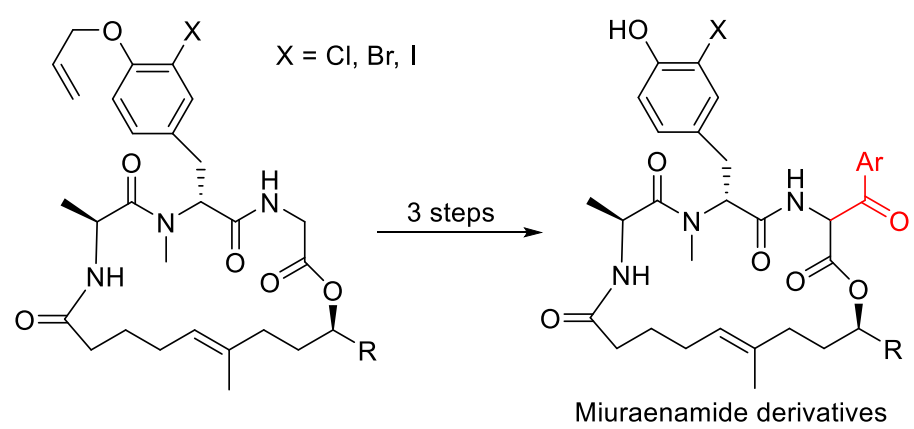

Scheme 1. Miuraenamides via late stage modifications.

In the miuraenamides the methyl-substituted double bond is at another position compared to all other cyclodepsipeptides (Figure 1). Therefore, we wanted to see what happens if we incorporate an "inverted" chondramide-type hydroxyacid with the same chain length. On the other hand, tripeptides with a $\mathrm{N}$ methylated amino acid in the central position should be easily accessible via Ugi reaction, ${ }^{36,37}$ a protocol used previously, e. g. for the synthesis of cyclic peptides. ${ }^{38-45}$ Although, these reactions should give mixtures of diastereomers, this is not a serious issue in this case, because one might expect that the different diastereomers should be separable, at least in the cyclized form. And in principle, all stereoisomers can be interesting candidates for SAR studies.

For the synthesis of the "inverted" polyketide fragment we started from the same building block 1, which was previously used during the synthesis of the miuraenamides. In this case $\mathbf{1}$ was converted into 2, which was coupled to the tripeptide and later on oxidized to the carboxylic acid which was subjected to cyclization (Scheme 2). Now, cleavage of the silyl protecting group, Swern oxidation and subsequent methyl Grignard addition gave rise to racemic secondary alcohol 4, which was subjected to enzymatic kinetic resolution. Both, the $(S)$-alcohol as well as the $(R)$-acetate $\mathbf{5}$ were obtained as pure enantiomer. Because we were only interested in (S)-4, $(R)-5$ was subjected to saponification, Mitsunobu reaction to $(S)-5$ and a second saponification provided finally additional (S)-4. Finally the methyl ester was converted into the corresponding allyl ester (S)-6 which could later on be cleaved without affecting the secondary ester.

The desired tripeptides 8 were obtained by Ugi reaction (Scheme 3). Besides phenylacetaldehyde (providing phenylalanine derivatives) also a range of aromatic aldehydes were used generating substituted aryl glycines (Table 1). Since arylglycines are known to be relatively sensitive to epimerization, we expected that the analogues cyclic depsipeptides might undergo "deracemization" towards the thermodynamically 
most stable stereoisomer, at least in some cases and the presence of base. This approach does not only allow the synthesis of $\mathrm{N}$-methylated central amino acids, but may be used also for all kind on $N$-substituents. Exemplarily also an allyl substituent was incorporated. Using allyl amine as one component provided the desired product in high yield, although the reaction took two days to go to completion (entry 1). To speed up the process we carried out the further Ugi reactions at higher temperature in the microwave ( $\mu \mathrm{W})$, and most reactions were finished in 30-90 $\mathrm{min}$. In most cases the yields obtained were only moderate, especially in case of the phenylacetaldehydes (entry 6), but the whole peptide 7 was obtained in only one step. All products were formed as almost 1:1 diastereomeric mixtures. Some of the derivatives could be separated by flash chromatography but the question was if this makes sense, because the next step was the saponification of the terminal methyl ester. As expected, the free tripeptide acids 8 were formed as a 1:1 mixture, independent if the ester was used in enantiomeric pure form or as stereoisomeric mixture, a clear indication for the configurational lability of the aryl glycine. Therefore, later on all esters $\mathbf{7}$ were saponified as diastereomeric mixtures.
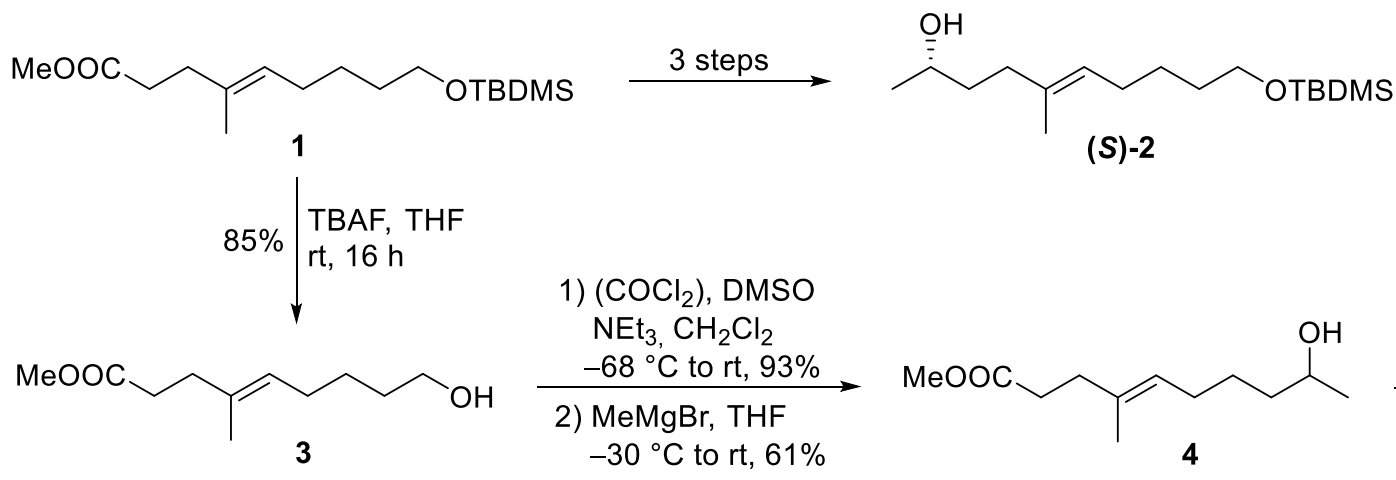

(S)-2

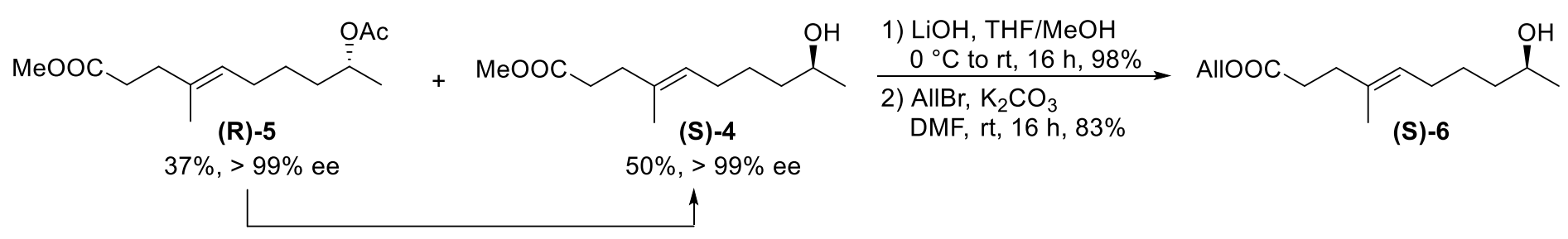

1) $\mathrm{K}_{2} \mathrm{CO}_{3}, \mathrm{MeOH}, \mathrm{rt}, 16 \mathrm{~h}, 74 \%$

2) $\mathrm{AcOH}, \mathrm{PPh}_{3}, \mathrm{DIAD}$

THF, $0{ }^{\circ} \mathrm{C}$ to $\mathrm{rt}, 16 \mathrm{~h}, 99 \%$

3) $\mathrm{K}_{2} \mathrm{CO}_{3}, \mathrm{MeOH}, \mathrm{rt}, 16 \mathrm{~h}, 67 \%$

Scheme 2. Synthesis of polyketide fragment (S)-6.

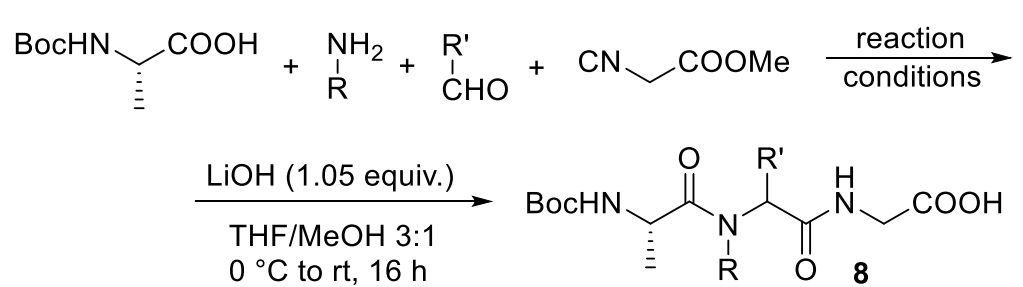<smiles>[R]C(C(=O)NCC(=O)OC)N([R])C(=O)[C@H](C)NC(=O)O</smiles>

Scheme 3. Synthesis of tripeptides via Ugi reaction. 
Table 1. Synthesis of tripeptides 8 via Ugi reaction/saponification

\begin{tabular}{|c|c|c|c|c|c|c|c|}
\hline Entry & $\mathrm{R}$ & $\mathrm{R}^{\prime}$ & reaction conditions & 7 & $\begin{array}{l}\text { Yield } \\
(\%) \\
\end{array}$ & 8 & $\begin{array}{l}\text { Yield } \\
(\%)\end{array}$ \\
\hline 1 & Allyl & $\mathrm{Ph}$ & $\mathrm{EtOH}, 0{ }^{\circ} \mathrm{C}$ to $\mathrm{rt}, 2 \mathrm{~d}$ & $7 a$ & 84 & $8 a$ & 90 \\
\hline 2 & $\mathrm{Me}$ & $\mathrm{Ph}$ & $\begin{array}{l}\mathrm{EtOH}, \mu \mathrm{W}, 150 \mathrm{~W} \\
80^{\circ} \mathrm{C}, 30 \mathrm{~min}\end{array}$ & $7 b$ & 66 & $8 b$ & 84 \\
\hline 3 & $\mathrm{Me}$ & 3-Br-4-allyloxy- $\mathrm{C}_{6} \mathrm{H}_{3}$ & $\mathrm{CF}_{3} \mathrm{CH}_{2} \mathrm{OH}, \mu \mathrm{W}, 150 \mathrm{~W}, 100^{\circ} \mathrm{C}, 75 \mathrm{~min}$ & 7c & 52 & $8 c$ & 93 \\
\hline 4 & $\mathrm{Me}$ & 3-Cl-4-allyloxy- $\mathrm{C}_{6} \mathrm{H}_{3}$ & $\mathrm{CF}_{3} \mathrm{CH}_{2} \mathrm{OH}, \mu \mathrm{W}, 150 \mathrm{~W}, 100^{\circ} \mathrm{C}, 90 \mathrm{~min}$ & $7 d$ & 28 & $8 d$ & 77 \\
\hline 5 & Me & 2-napth & $\mathrm{CHCl}_{3}, \mu \mathrm{W}, 150 \mathrm{~W}, 80^{\circ} \mathrm{C}, 30 \mathrm{~min}$ & $7 e$ & 36 & $8 e$ & $>99$ \\
\hline 6 & Me & $\mathrm{Bn}$ & $\mathrm{C}_{2} \mathrm{H}_{4} \mathrm{Cl}_{2}, \mu \mathrm{W}, 150 \mathrm{~W}, 100^{\circ} \mathrm{C}, 120 \mathrm{~min}$ & $7 f$ & 33 & $8 f$ & 65 \\
\hline
\end{tabular}

The tripeptide acids $\mathbf{8}$ were subsequently coupled with polyketide (S)-6 to $\mathbf{9}$ using the Steglich protocol (Scheme 4, Table 2). ${ }^{46}$ To be able to compare the new miuraenamides with the inverted polyketide directly with the natural products, we also coupled (S)-6 with the original tripeptide containing 4-allyloxy-3-bromotyrosine (8g). After cleavage of the allyl ester $\mathbf{1 0}$ with $\mathrm{Pd}\left(\mathrm{PPh}_{3}\right)_{4} /$ morpholine the free acid $\mathbf{1 1}$ was activated as pentafluorophenyl ester according to Schmidt et. al. ${ }^{47,48}$ The Boc-protecting group was removed with trifluoroacetic acid and the salt solution was added dropwise to a vigorously stirred suspension of $\mathrm{CHCl}_{3}$ and sat. $\mathrm{NaHCO}_{3}$ solution. Stirring overnight gave rise to the desired macrocyclic products 11 . An indeed, our expectations became fulfilled, at least in part.

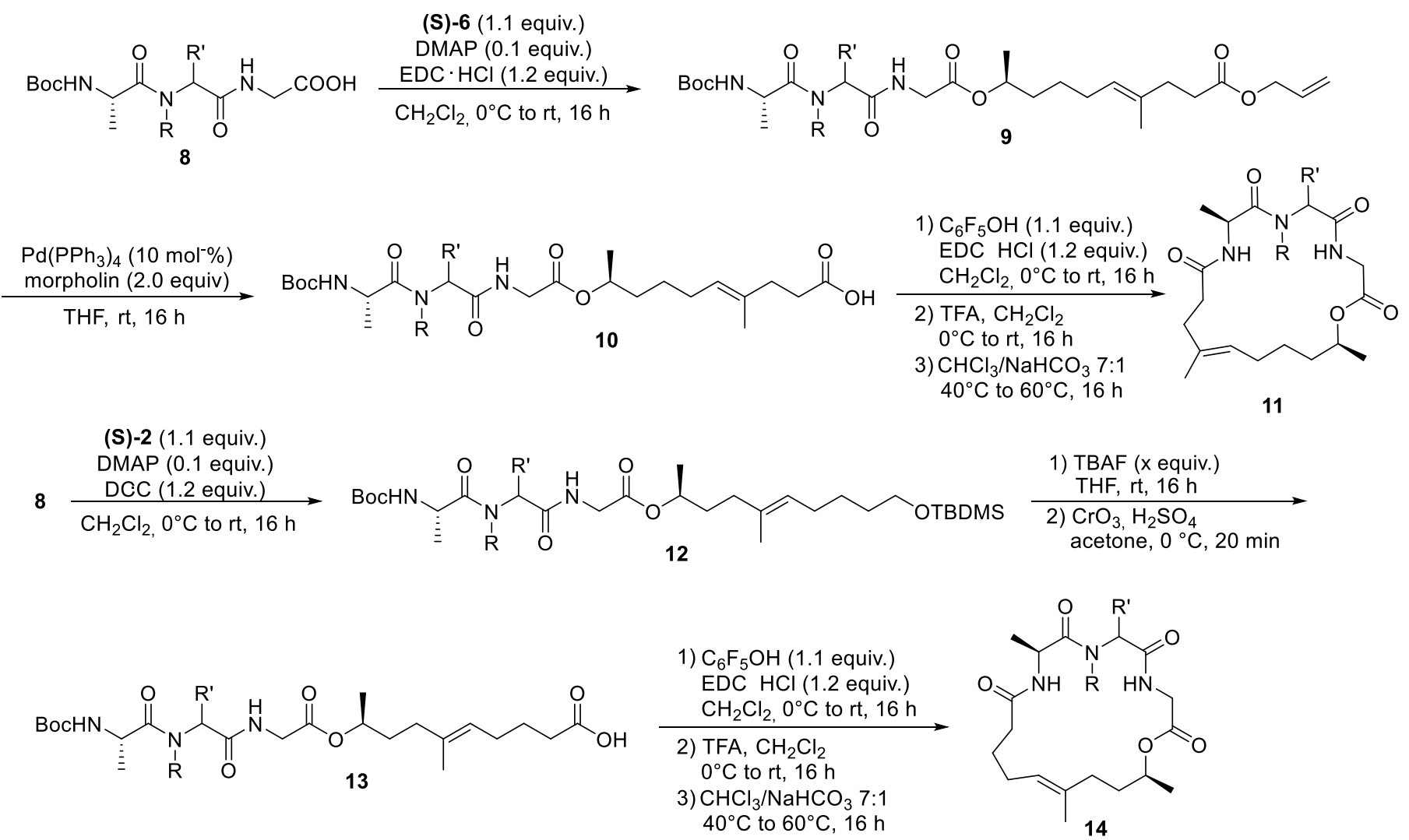

Scheme 4. Synthesis of miuraenamide derivatives 11 and 14. 
Table 2. Synthesis of miuraenamide derivatives $\mathbf{1 1}$ and $\mathbf{1 5}$

\begin{tabular}{|c|c|c|c|c|c|c|c|c|c|c|c|}
\hline Entry & $2 / 6$ & 8 & $\mathrm{R}$ & $\mathrm{R}^{\prime}$ & $9 / 12$ & $\begin{array}{l}\text { Yield } \\
(\%)\end{array}$ & $10 / 13$ & $\begin{array}{l}\text { Yield } \\
(\%)\end{array}$ & $11 / 14$ & d.r. & $\begin{array}{l}\text { Yield } \\
(\%)\end{array}$ \\
\hline 1 & $(S)-6$ & $8 a$ & Allyl & $\mathrm{Ph}$ & $9 a$ & 63 & $10 a$ & 60 & $11 a$ & $1: 1$ & 41 \\
\hline 2 & $(S)-6$ & $8 b$ & Me & $\mathrm{Ph}$ & $9 b$ & 67 & $10 \mathrm{~b}$ & 52 & $11 b$ & $9: 1$ & 44 \\
\hline 3 & $(S)-6$ & $8 c$ & $\mathrm{Me}$ & 3-Br-4-allyloxy- $\mathrm{C}_{6} \mathrm{H}_{3}$ & $9 c$ & 60 & $10 c^{(a)}$ & 83 & 11c & -- & -- \\
\hline 4 & $(S)-6$ & $8 d$ & Me & 3-Cl-4-allyloxy- $\mathrm{C}_{6} \mathrm{H}_{3}$ & $9 d$ & 60 & $10 d^{(a)}$ & 98 & $11 d^{(a)}$ & $7: 3$ & 38 \\
\hline 5 & $(S)-6$ & $8 e$ & Me & 2-napth & $9 e$ & 59 & $10 \mathrm{e}$ & 98 & $11 \mathrm{e}$ & $1: 1$ & 13 \\
\hline 6 & $(S)-6$ & $8 f$ & $\mathrm{Me}$ & $\mathrm{Bn}$ & $9 f$ & 60 & $10 f$ & 98 & $11 f$ & $1: 1$ & $27+26^{(b)}$ \\
\hline 7 & $(S)-6$ & $8 g$ & Me & $\begin{array}{l}(R)-3-\mathrm{Br} \text {-4-allyloxy- } \\
\mathrm{C}_{6} \mathrm{H}_{3} \mathrm{CH}_{2}\end{array}$ & $9 g$ & 49 & $10 \mathrm{~g}^{(\mathrm{a})}$ & 98 & $11 g^{(a)}$ & $>99: 1$ & 9 \\
\hline 8 & $(S)-2$ & $8 d$ & $\mathrm{Me}$ & 3-Cl-4-allyloxy- $\mathrm{C}_{6} \mathrm{H}_{3}$ & $12 d$ & 47 & $13 d$ & 46 & 14d & $66: 34$ & 71 \\
\hline 9 & $(S)-2$ & $8 e$ & Me & 2-napth & $12 \mathrm{e}$ & 74 & $13 e$ & 68 & $14 \mathrm{e}$ & $78: 22$ & 46 \\
\hline
\end{tabular}

(a) without an phenolic allyl protecting group. (b) Yields of the separated diastereomers.

While during the whole sequence the diastereomeric ratios of the tripeptides $\mathbf{7}$ and $\mathbf{8}$ were in all cases around 1:1, 11b was obtained as a 9:1 diastereomeric mixture. Surprisingly the ratio for the corresponding $N$ allyl derivative 11a was unchanged. Obviously, in case of $\mathbf{1 1 b}$ an equilibration occurred either during cyclization or afterwards. This effect was also observed with several other derivatives, although not in such a high ratio. In case of the halogenated allyl ethers $10 \mathrm{c}, \mathbf{1 0 \mathrm { d }}$ and $\mathbf{1 0 \mathrm { g }}$, both allyl protecting groups were removed simultaneously, and probably the free phenolic group caused problems in the cyclization step, especially for the bromo derivatives. In case of $\mathbf{1 0 g}$ the yield of the macrocycle was rather low, and the reaction of $10 \mathrm{c}$ resulted in complete decomposition of the substrate, while the corresponding chloro derivative $10 \mathrm{~d}$ caused no significant problems.

Exemplarily, some of the tripeptides $\mathbf{8}$ were also coupled with the original polyketide precursor (S)-2 to figure out the influence of the side chain on the activity. Besides an unpolar naphthyl sidechain, also a protected chlorophenol was incorporated, which should be close to the natural substituent in miuraenamide $\mathrm{C}$, missing only the benzylic carbon. In this case the allyl-protected phenol was subjected to cyclization, which occurred in excellent $71 \%$, a further indication, that the free $\mathrm{OH}$-group might be the critical functionality. Finally, the phenolic allyl protecting group of $\mathbf{1 4 d}$ was cleaved using $\mathrm{CpRu}(\mathrm{MeCN})_{3} \mathrm{PF}_{6}$ as a catalyst (Scheme 5). ${ }^{49}$
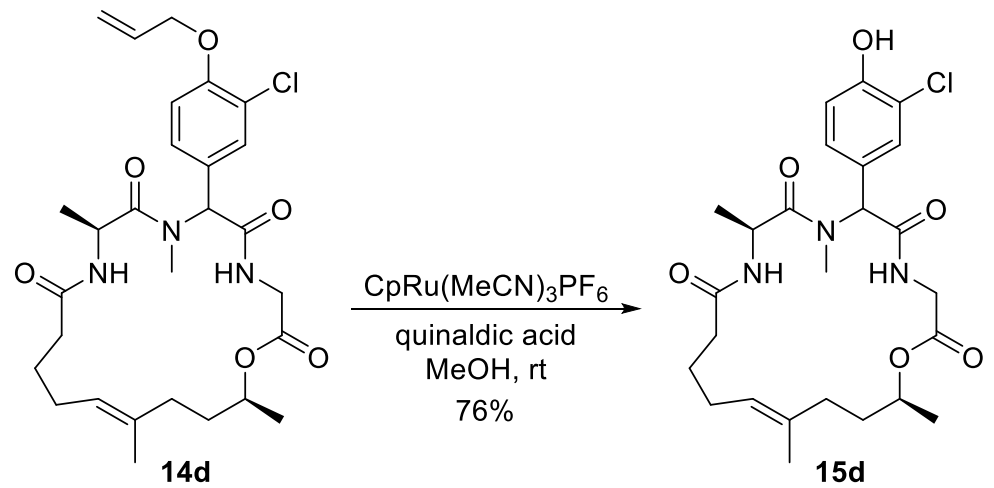

Scheme 5. Deprotected of allyl-protected cyclopeptide $\mathbf{1 4 d .}$ 
The cytotoxicity of all new cyclic miuraenamide derivatives was investigated using two human cancer cell lines, HCT-116 (colon cancer) and U-2 OS (osteosarcoma). Some representative results are summarized in Table 3. For comparison, also the data for the simplified, highly active derivatives 16a/b (Figure 2, entries 6 and 7) are shown. Interestingly, all new derivatives showed a comparable cytotoxicity in the mid $\mu \mathrm{M}$ range, far away from the activity of the simplified miuraenamides 16. Although the bromo derivative 16a is significantly more active than the chloro analogue $16 \mathrm{~b}$, even this compound is around 1000-fold more active than the best new derivative (entry 1 ). Obviously modification at the central position of the tripeptide as well as in the polyketide fragment are not tolerated, independent if polar or unpolar groups are introduced. Even derivative $11 \mathrm{~g}$ with the correct tripeptide was as inactive as all the others. Even if the same substitution pattern is used as in the miuraenamides, removal of the benzylic $\mathrm{CH}_{2}$-groups is also not accepted (entry 6 vs. 8).

Table 3. Cytotoxicity of miuraenamides 11 and 14-16

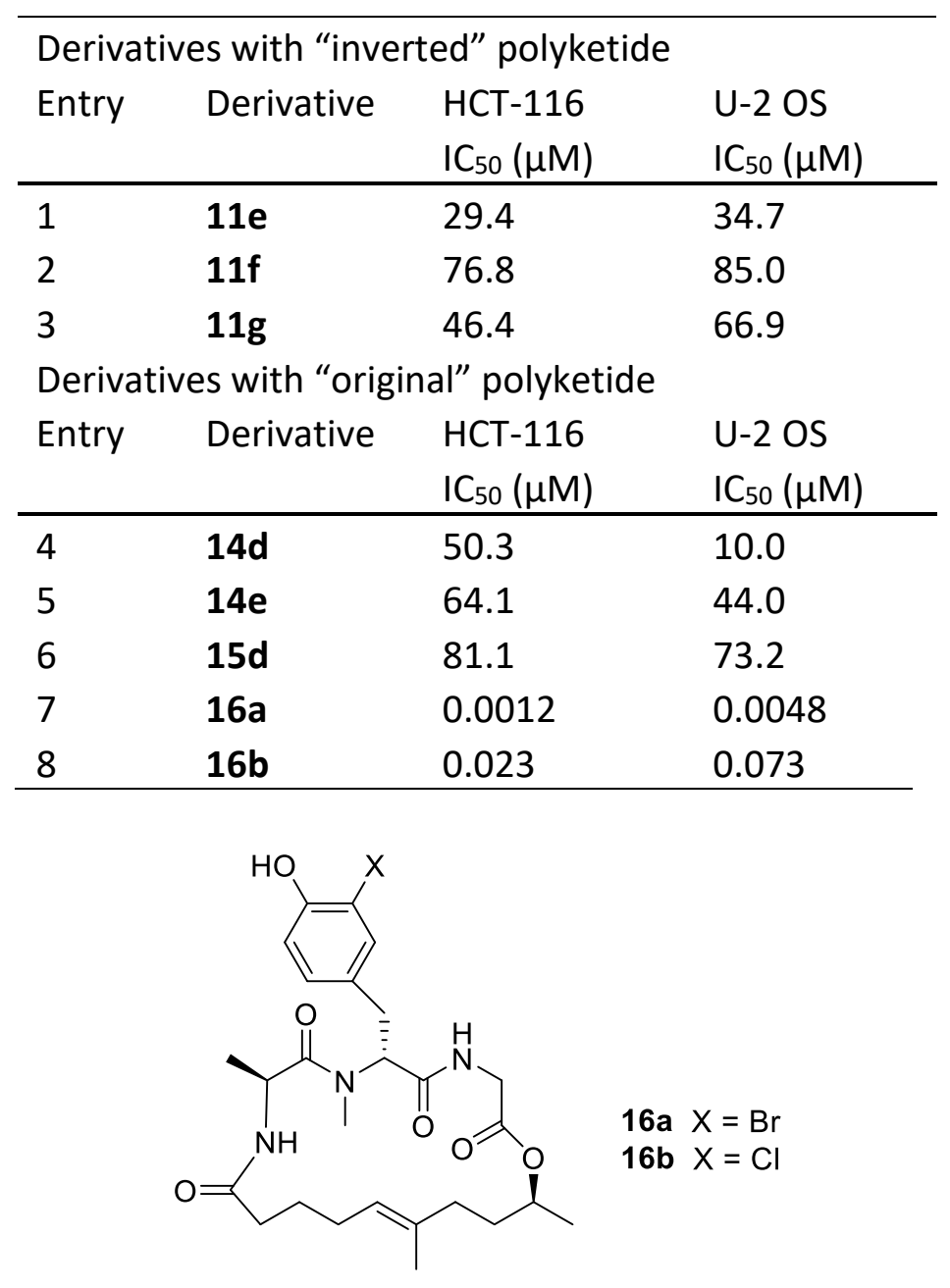

Figure 2. Highly cytostatic simplified miuraenamide derivatives.

\section{Conclusions}

In conclusion, we could show that Ugi reactions provide easily tripeptides which can directly be incorporated into new miuraenamide derivatives. Although the yields are moderate in certain cases, application of 
microwave heating speeds up the reaction significantly providing acceptable yields. Detailed SAR studies indicate that modifications at the $C$-terminus are well accepted, but not at the central position. Replacing the hydroxy acid by a geodiamolide- or chondramide-type polyketide fragment (inverted polyketide) is also not tolerated. All new derivatives synthesized showed comparable cytotoxicity in the mid $\mu \mathrm{M}$ range, which is at least 1000-fold lower than comparable simplified miuraenamide derivatives. Further investigations, especially regarding the binding mode, are in progress.

\section{Experimental Section}

General. All air- or moisture-sensitive reactions were carried out in dried glassware $\left(>100{ }^{\circ} \mathrm{C}\right)$ under an atmosphere of nitrogen. Dried solvents were distilled before use: Dichloromethane was purchased from Sigma-Aldrich. The products were purified by flash chromatography on silica gel (0.063-0.2 mm). Mixtures of EtOAc and petroleum ether were generally used as eluents. Analytical TLC was performed on pre-coated silica gel plates (Macherey-Nagel, Polygram ${ }^{\circledR}$ SIL G/UV254). Visualization was accomplished with UV-light and $\mathrm{KMnO}_{4}$ or Ninhydrin solution. Melting points were determined with a Laboratory Devices MEL-TEMP // melting point apparatus and are uncorrected. ${ }^{1} \mathrm{H}$ and ${ }^{13} \mathrm{C}$ NMR spectra were recorded with Bruker AV // 400 [400 MHz $\left({ }^{1} \mathrm{H}\right)$ and $\left.100 \mathrm{MHz}\left({ }^{13} \mathrm{C}\right)\right]$ and Bruker DRX and $A V 500\left[500 \mathrm{MHz}\left({ }^{1} \mathrm{H}\right)\right.$ and $\left.125 \mathrm{MHz}\left({ }^{13} \mathrm{C}\right)\right]$ spectrometers in $\mathrm{CDCl}_{3}$, unless otherwise specified. Chemical shifts are reported in ppm relative to $\mathrm{TMS}$, and $\mathrm{CHCl}_{3}$ was used as the internal standard. Melting points were determined with a MEL-TEMP II (Laboratory Devices) melting point apparatus and are uncorrected. ${ }^{1} \mathrm{H}$ and ${ }^{13} \mathrm{C} N M R$ spectra were recorded with Bruker AV I/ $400\left[400 \mathrm{MHz}\left({ }^{1} \mathrm{H}\right)\right.$ and $\left.100 \mathrm{MHz}\left({ }^{13} \mathrm{C}\right)\right]$ and Bruker DRX and $A V 500\left[500 \mathrm{MHz}\left({ }^{1} \mathrm{H}\right)\right.$ and $\left.125 \mathrm{MHz}\left({ }^{13} \mathrm{C}\right)\right]$ spectrometers in $\mathrm{CDCl}_{3}$, unless otherwise specified. Chemical shifts are reported in ppm relative to $\mathrm{TMS}$, and $\mathrm{CHCl}_{3}$ was used as the internal standard. Mass spectra were recorded with a Finnigan MAT 95 spectrometer (quadrupole) using the $\mathrm{Cl}$ technique.

(4E)-9-Hydroxy-4-methyl-4-nonenoic acid methyl ester (3). Silylether 1 (1.02 g, $3.24 \mathrm{mmol})$ was dissolved in THF $(6.5 \mathrm{~mL})$ before TBAF $3 \mathrm{H}_{2} \mathrm{O}(1.23 \mathrm{~g}, 3.89 \mathrm{mmol})$ in THF $(7 \mathrm{~mL})$ was added. After stirring overnight the solution was diluted with ethyl acetate $(20 \mathrm{~mL})$ and was washed with $1 \mathrm{~N} \mathrm{HCl}$ solution, brine and dried $\left(\mathrm{Na}_{2} \mathrm{SO}_{4}\right)$. After evaporation of the solvent in vacuo and flash chromatography (silica, hexanes:ethyl acetate 1:1) alcohol 3 (550 mg, $2.75 \mathrm{mmol}, 85 \%)$ was obtained as colorless oil. $R_{f}(3)=0.36$ (silica, hexanes:ethyl acetate 1:1). ${ }^{1} \mathrm{H}$ NMR (400 MHz, $\left.\mathrm{CDCl}_{3}\right): \delta=1.40(\mathrm{~m}, 2 \mathrm{H}), 1.55(\mathrm{~m}, 2 \mathrm{H}), 1.61(\mathrm{~s}, 3 \mathrm{H}), 2.01(\mathrm{td}, J 7.3,7.3 \mathrm{~Hz}, 2$ H), $2.31(\mathrm{t}, J 7.2 \mathrm{~Hz}, 2 \mathrm{H}), 2.42(\mathrm{~m}, 2 \mathrm{H}), 3.64(\mathrm{t}, J 6.8 \mathrm{~Hz}, 2 \mathrm{H}), 3.67(\mathrm{~s}, 3 \mathrm{H}), 5.17(\mathrm{tq}, J 7.3 \mathrm{~Hz}, 1.3 \mathrm{~Hz}, 1 \mathrm{H}) \mathrm{ppm}$. ${ }^{13} \mathrm{C} \mathrm{NMR}\left(100 \mathrm{MHz}, \mathrm{CDCl}_{3}\right): \delta=15.9(\mathrm{q}), 25.8(\mathrm{t}), 27.5(\mathrm{t}), 32.3(\mathrm{t}), 33.0(\mathrm{t}), 34.7(\mathrm{t}), 51.5(\mathrm{q}), 62.9(\mathrm{t}), 125.2(\mathrm{~d})$, 133.6 (s), 173.9 (s) ppm. HRMS (Cl) calc. for $\mathrm{C}_{11} \mathrm{H}_{21} \mathrm{O}_{3}{ }^{+}[\mathrm{M}+\mathrm{H}]^{+}:$: 201.1485, found 201.1469.

(4E)-9-Hydroxy-4-methyl-4-decenoic acid methyl ester (rac-4). Oxalyl chloride (3.63 mL, $43.2 \mathrm{mmol}$ ) in dichloromethane $(70 \mathrm{~mL})$ was cooled to $-68{ }^{\circ} \mathrm{C}$ before DMSO $(6.14 \mathrm{~mL}, 86.4 \mathrm{mmol})$ in dichloromethane (15 $\mathrm{mL}$ ) was added in such a rate that a temperature of $-68{ }^{\circ} \mathrm{C}$ was not passed over. 5 Minutes after complete addition the alcohol 3 was added in dichloromethane $(22 \mathrm{~mL})$ and stirring was continued fur further $30 \mathrm{~min}$. $\mathrm{NEt}_{3}(20 \mathrm{~mL}, 144 \mathrm{mmol}$ ) was added and the mixture was allowed to warm to room temperature overnight. The solution was hydrolyzed and the aqueous layer was extracted trice with dichloromethane and ethyl acetate (20 $\mathrm{mL}$ each). The organic layer was dried $\left(\mathrm{Na}_{2} \mathrm{SO}_{4}\right)$ and after evaporation of the solvent in vacuo and flash chromatography (silica, hexanes:ethyl acetate 7:3) the corresponding aldehyde (5.33 g, $26.9 \mathrm{mmol}, 93 \%$ ) was obtained as pale yellow oil and directly used in the subsequent Grignard reaction. 
The aldehyde $(890 \mathrm{mg}, 4.06 \mathrm{mmol})$ was dissolved in THF $(16 \mathrm{~mL})$ and cooled to $-30{ }^{\circ} \mathrm{C}$ before $\mathrm{MeMgBr}(4.9 \mathrm{~mL}$, $4.90 \mathrm{mmol}, 1 \mathrm{M}$ in $\mathrm{Bu}_{2} \mathrm{O}$ ) was added dropwise. Stirring was continued for further 30 min before the reaction mixture was warmed up to room temperature and hydrolyzed with $1 \mathrm{M} \mathrm{NH}_{4} \mathrm{Cl}(20 \mathrm{~mL})$. The aqueous layer was extracted trice with ether $(15 \mathrm{~mL})$ and the combined organic layers were dried $\left(\mathrm{Na}_{2} \mathrm{SO}_{4}\right)$ and evaporated in vacuo. Flash chromatography (silica, hexanes:ethyl acetate 6:4) provided racemic alcohol 4 (530 mg, 2.48 $\mathrm{mmol}, 61 \%$ d. Th.) as colorless oil. $\mathrm{R}_{\mathrm{f}}(4)=0.28$ (hexanes:ethyl acetate $6: 4$ ). HPLC (Chiracel OD-H, hexane/ipropanol 95:5, $\left.10{ }^{\circ} \mathrm{C}, 1 \mathrm{~mL} / \mathrm{min}, 210 \mathrm{~nm}\right): \mathrm{t}_{\mathrm{R}}[(\boldsymbol{S})-4]=10.15 \mathrm{~min}, \mathrm{t}_{\mathrm{R}}[(\boldsymbol{R})-4]=11.31 \mathrm{~min} .{ }^{1} \mathrm{H} \mathrm{NMR}(400 \mathrm{MHz}$, $\left.\mathrm{CDCl}_{3}\right): \delta=1.19(\mathrm{~d}, J 6.0 \mathrm{~Hz}, 3 \mathrm{H}), 1.39-1.47(\mathrm{~m}, 4 \mathrm{H}), 1.61(\mathrm{~s}, 3 \mathrm{H}), 2.00(\mathrm{td}, J 6.5,6.5 \mathrm{~Hz}, 2 \mathrm{H}), 2.31(\mathrm{t}, J 8.0 \mathrm{~Hz}, 2$ $\mathrm{H}), 2.42(\mathrm{~m}, 2 \mathrm{H}), 3.67(\mathrm{~s}, 3 \mathrm{H}), 3.79(\mathrm{~m}, 1 \mathrm{H}), 5.16(\mathrm{td}, J$ 7.2, $0.8 \mathrm{~Hz}, 1 \mathrm{H}) \mathrm{ppm} .{ }^{13} \mathrm{C} \mathrm{NMR}\left(100 \mathrm{MHz}, \mathrm{CDCl}_{3}\right): \delta=$ $15.9(\mathrm{q}), 23.5(\mathrm{q}), 25.8(\mathrm{t}), 27.7(\mathrm{t}), 33.0(\mathrm{t}), 34.7(\mathrm{t}), 38.8(\mathrm{t}), 51.5(\mathrm{q}), 68.1(\mathrm{~d}), 125.2(\mathrm{~d}), 133.5(\mathrm{~s}), 173.9(\mathrm{~s})$ ppm. HRMS (Cl) calc. for $\mathrm{C}_{12} \mathrm{H}_{23} \mathrm{O}_{3}{ }^{+}[\mathrm{M}+\mathrm{H}]^{+}:$: 215.1642, found 215.1640 .

(9S,4E)-9-Hydroxy-4-methyl-4-decenoic acid methyl ester [(S)-4]. Racemic alcohol rac-4 (2.84 g,13.3 mmol) was dissolved in vinyl acetate $(6.1 \mathrm{~mL}, 66.5 \mathrm{mmol}$ ) before Novozym 435 (28 mg) was added. The solution was shaken at room temperature and the reaction was monitored by HPLC. After $20 \mathrm{~h}$ the solution was filtered and the Novozym was washed with ether. After evaporation of the solvent in vacuo, flash chromatography (silica, hexanes:ethyl acetate 9:1, 6:4) provided (S)-4 (1.43 g, $6.65 \mathrm{mmol}, 50 \%,>99.9 \%$ ee) as colorless oil. $\mathrm{R}_{\mathrm{f}}[(\boldsymbol{S})-\mathbf{4}]=$ 0.19 (hexanes:ethyl acetate 9:1). $[a]_{1}^{30}=+6.0\left(\mathrm{c}=1.0, \mathrm{CHCl}_{3}\right)$. NMR and analytical data are analogous to rac-4.

$(\mathbf{9}, \mathbf{4 E})-9-A c e t o x y-4-m e t h y l-4-d e c e n o i c ~ a c i d ~ m e t h y l ~ e s t e r ~[(R)-5]$. Acetate $(\boldsymbol{R})-\mathbf{5}(1.26 \mathrm{~g}, 4.91 \mathrm{mmol}, 37 \% \mathrm{~d}$. Th., $>99 \%$ ee) was obtained as second product in the enzymatic kinetic resolution of rac-4 as colorless oil. $R_{f}$ $[(\boldsymbol{R})-5]=0.42$ (hexanes:ethyl acetate 9:1). $[a]_{0}^{20}=+4.3\left(\mathrm{c}=1.0, \mathrm{CHCl}_{3}\right) . \mathrm{GC}\left(\right.$ Chirasil-Dex-CB: $\mathrm{T}_{0}(3 \mathrm{~min})=80^{\circ} \mathrm{C}, 2$ ${ }^{\circ} \mathrm{C} / \mathrm{min}$ to $\mathrm{T}=200{ }^{\circ} \mathrm{C}(3 \mathrm{~min})$, injektor: $\mathrm{T}=250{ }^{\circ} \mathrm{C}$, detektor: $\left.\mathrm{T}=275^{\circ} \mathrm{C}\right): \mathrm{t}_{\mathrm{R}}[(\boldsymbol{S})-5]=23.13 \mathrm{~min}, \mathrm{t}_{\mathrm{R}}[(\boldsymbol{R})-5]=23.39$ min. ${ }^{1} \mathrm{H}$ NMR $\left(400 \mathrm{MHz}, \mathrm{CDCl}_{3}\right): \delta=1.20(\mathrm{~d}, J 6.4 \mathrm{~Hz}, 3 \mathrm{H}), 1.35(\mathrm{~m}, 2 \mathrm{H}), 1.47(\mathrm{~m}, 2 \mathrm{H}), 1.60(\mathrm{~s}, 3 \mathrm{H}), 1.98(\mathrm{dt}, J$ 7.2, 7.2 Hz, $2 \mathrm{H}), 2.03(\mathrm{~s}, 3 \mathrm{H}), 2.30(\mathrm{t}, J 8.0 \mathrm{~Hz}, 2 \mathrm{H}), 2.42(\mathrm{~m}, 2 \mathrm{H}), 3.67(\mathrm{~s}, 3 \mathrm{H}), 4.88(\mathrm{~m}, 1 \mathrm{H}), 5.14(\mathrm{td}, J 7.3,1.2$ $\mathrm{Hz}, 1 \mathrm{H}) \mathrm{ppm} .{ }^{13} \mathrm{C} \mathrm{NMR}\left(100 \mathrm{MHz}, \mathrm{CDCl}_{3}\right): \delta=15.9(\mathrm{q}), 20.0(\mathrm{q}), 21.4(\mathrm{q}), 25.5(\mathrm{t}), 27.6(\mathrm{t}), 33.0(\mathrm{t}), 34.6(\mathrm{t}), 35.5$ (t), 51.5 (q), 70.9 (d), 125.0 (d), 133.7 (s), 170.8 (s), 173.9 (s) ppm. HRMS (Cl) calc. for $\mathrm{C}_{14} \mathrm{H}_{25} \mathrm{O}_{4}{ }^{+}[\mathrm{M}+\mathrm{H}]^{+}$: 257.1747, found 257.1751 .

(9S,4E)-9-Hydroxy-4-methyl-4-decenoic acid allyl ester [(S)-6]. Methyl ester (S)-4 (1.42 g, 6.65 mmol) was dissolved in THF $(6.7 \mathrm{~mL})$ and a $1 \mathrm{M} \mathrm{LiOH}$ solution in THF $(8.7 \mathrm{~mL}, 8.7 \mathrm{mmol})$ was added. The solution was stirred overnight at room temperature before it was diluted with ethyl acetate $(20 \mathrm{~mL})$. The organic layer was washed trice with water. The combined aqueous layers were acidified with $1 \mathrm{M} \mathrm{HCl}$ and extracted trice with dichloromethane $\left(15 \mathrm{~mL}\right.$ each). The combined organic layers were dried $\left(\mathrm{Na}_{2} \mathrm{SO}_{4}\right)$ and the solvent was evaporated in vacuo providing the corresponding acid $(1.13 \mathrm{~g}, 5.64 \mathrm{mmol}, 85 \%)$. This acid was dissolved in DMF $(12 \mathrm{~mL})$ and reacted with $\mathrm{K}_{2} \mathrm{CO}_{3}(530 \mathrm{mg}, 6.29 \mathrm{mmol})$ and allyl bromide $(740 \mathrm{mg}, 8.58 \mathrm{mmol})$. The solution was stirred overnight at room temperature, diluted with ethyl acetate $(20 \mathrm{~mL})$ and washed trice with water and once with $1 \mathrm{M} \mathrm{KHSO}_{4}$. After drying the organic layer $\left(\mathrm{Na}_{2} \mathrm{SO}_{4}\right)$ and evaporation of the solvent in vacuo flash chromatography (silica, hexanes:ethyl acetate 6:4) provided allyl ester (S)-6 (1.13 g, $4.72 \mathrm{mmol}$, $83 \%$ ) as a pale yellow oil. $\mathrm{R}_{\mathrm{f}}[(\mathbf{S})-6]=0.34$ (hexanes:ethyl acetate 6:4). $[a]^{]}=+5.6\left(\mathrm{c}=1.0, \mathrm{CHCl}_{3}\right) .{ }^{1} \mathrm{H} \mathrm{NMR}(400$ $\left.\mathrm{MHz}_{\mathrm{CDCl}}\right): \delta=1.19(\mathrm{~d}, J 6.2 \mathrm{~Hz}, 3 \mathrm{H}), 1.38-1.48(\mathrm{~m}, 4 \mathrm{H}, 3-\mathrm{H}), 1.62(\mathrm{~s}, 3 \mathrm{H}), 2.0(\mathrm{td}, J 6.8,6.8 \mathrm{~Hz}, 2 \mathrm{H}), 2.32(\mathrm{t}$, J $8.0 \mathrm{~Hz}, 2 \mathrm{H}), 2.45(\mathrm{t}, J 7.8 \mathrm{~Hz}, 2 \mathrm{H}), 3.80(\mathrm{~m}, 1 \mathrm{H}), 4.58(\mathrm{dt}, J 5.5,1.5 \mathrm{~Hz}, 2 \mathrm{H}), 5.16$ (td, J 7.0, $1.0 \mathrm{~Hz}, 1 \mathrm{H}), 5.24$ $\left(\mathrm{dd}, J_{1}=10.5,1.2 \mathrm{~Hz}, 1 \mathrm{H}\right), 5.32(\mathrm{dd}, J 17.1,1.5 \mathrm{~Hz}, 1 \mathrm{H}), 5.92(\mathrm{ddt}, J 17.1,10.5,5.8 \mathrm{~Hz}, 1 \mathrm{H}) \mathrm{ppm} .{ }^{13} \mathrm{C} \mathrm{NMR}(100$ $\left.\mathrm{MHz}_{2} \mathrm{CDCl}_{3}\right): \delta=15.9(\mathrm{q}), 23.5(\mathrm{q}), 25.8(\mathrm{t}), 27.7(\mathrm{t}), 33.1(\mathrm{t}), 34.6(\mathrm{t}), 38.8(\mathrm{t}), 65.0(\mathrm{t}), 68.0(\mathrm{~d}), 118.1(\mathrm{t}), 125.2$ (d), $132.3(\mathrm{~d}), 133.5$ (s), 173.1 (s) ppm. HRMS (Cl) calc. for $\mathrm{C}_{14} \mathrm{H}_{25} \mathrm{O}_{3}{ }^{+}[\mathrm{M}+\mathrm{H}]^{+}:$: 241.1798, found 241.1803. 
$\boldsymbol{N}$-tert-Butoxycarbonyl-(S)-alanyl-( $\mathbf{N}$-allyl-phenylglycyl)-glycine methyl ester (7a). Benzaldehyde $(0.51 \mathrm{~mL}$, $5.00 \mathrm{mmol})$, allylamine $(0.38 \mathrm{~mL}, 5.00 \mathrm{mmol})$ and $\mathrm{N}$-Boc-Ala-OH $(950 \mathrm{mg}, 5.00 \mathrm{mmol}$ ) were dissolved in ethanol $(5 \mathrm{~mL})$ before methyl isocyanoacetate $(0.45 \mathrm{~mL}, 5.00 \mathrm{mmol})$ was added at $0{ }^{\circ} \mathrm{C}$. The clear solution was stirred for two days at room temperature before it was diluted with dichloromethane (30 $\mathrm{mL})$. The organic phase was washed with sat. $\mathrm{NaHCO}_{3}(20 \mathrm{~mL})$ and $1 \mathrm{M} \mathrm{KHSO}_{4}(20 \mathrm{~mL})$, dried $\left(\mathrm{Na}_{2} \mathrm{SO}_{4}\right)$ and evaporated in vacuo. Flash chromatography (silica, hexanes:ethyl acetate $1: 1)$ provided tripeptide $7 \mathrm{a}(1.82 \mathrm{~g}, 4.20 \mathrm{mmol}, 84 \%)$ as a 56:44 diastereomeric mixture. Colorless solid, $m p 36-38{ }^{\circ} \mathrm{C} . R_{f}(7 a)=0.17$ (hexanes:ethyl acetate 1:1). Diastereomer 1: ${ }^{1} \mathrm{H}$ NMR $\left(\mathrm{CDCl}_{3}, 400 \mathrm{MHz}\right): \delta=1.29(\mathrm{~d}, J 6.8 \mathrm{~Hz}, 3 \mathrm{H}), 1.43(\mathrm{~s}, 9 \mathrm{H}), 3.76(\mathrm{~s}, 3 \mathrm{H}), 3.91-4.21(\mathrm{~m}$, $4 \mathrm{H}), 4.43(\mathrm{q}, J \mathrm{~J} .0,1 \mathrm{H}), 4.96(\mathrm{~d}, J$ 10.8, $1 \mathrm{H}), 5.02(\mathrm{~d}, J$ 18.3, $1 \mathrm{H}), 5.19(\mathrm{bs}, 1 \mathrm{H}), 5.27(\mathrm{~m}, 1 \mathrm{H}), 6.17(\mathrm{~s}, 1 \mathrm{H}), 7.17$ (bs, $1 \mathrm{H}), 7.32-7.43(\mathrm{~m}, 5 \mathrm{H}) \mathrm{ppm} .{ }^{13} \mathrm{C} \mathrm{NMR}\left(\mathrm{CDCl}_{3}, 100 \mathrm{MHz}\right): \delta=17.9(\mathrm{q}), 28.3(3 \mathrm{q}), 41.2(\mathrm{t}), 46.7$ (d), $48.8(\mathrm{t})$, 52.2 (q), 62.5 (d), 80.1 (s), 117.2 (t), 128.4 (d), 128.7 (d), 130.1 (d), 133.5 (s), 156.1 (s), 169.6 (s), 170.1 (s), 175.1 (s) ppm. Diastereomer 2: ${ }^{1} \mathrm{H} N M R\left(\mathrm{CDCl}_{3}, 400 \mathrm{MHz}\right): \delta=1.35\left(\mathrm{~d}, J_{2,1}=6.5,3 \mathrm{H}\right), 1.43(\mathrm{~s}, 9 \mathrm{H}), 3.74(\mathrm{~s}, 3 \mathrm{H})$, 3.80-4.31 (m, $4 \mathrm{H}), 4.61(\mathrm{q}, J$ 7.3, $1 \mathrm{H}), 4.96(\mathrm{~d}, J$ 10.8, $1 \mathrm{H}), 5.02(\mathrm{~d}, J$ 18.3, $1 \mathrm{H}), 5.36(\mathrm{~d}, J$ 8.3, $1 \mathrm{H}), 5.59(\mathrm{~m}, 1$ $\mathrm{H}), 6.06(\mathrm{~s}, 1 \mathrm{H}), 6.35$ (bs, $1 \mathrm{H}), 7.32-7.43(\mathrm{~m}, 5 \mathrm{H}) \mathrm{ppm} .{ }^{13} \mathrm{CNMR}\left(\mathrm{CDCl}_{3}, 100 \mathrm{MHz}\right): \delta=19.1$ (q), $28.3(\mathrm{q}), 41.3$ $(\mathrm{t}), 46.9$ (d), 48.7 (t), 52.3 (q), 62.0 (d), 79.5 (s), 117.1 (t), 128.4 (d), 128.8 (d), 129.5 (d), 134.2 (s), 156.1 (s), 169.5 (s), 169.9 (s), 174.8 (s) ppm. HRMS (Cl) calc. for $\mathrm{C}_{22} \mathrm{H}_{32} \mathrm{~N}_{3} \mathrm{O}_{6}{ }^{+}[\mathrm{M}+\mathrm{H}]^{+}:$: 434.2286, found 434.2313.

$\mathbf{N}$-tert-Butoxycarbonyl-(S)-alanyl-[N-methyl-2-naphthylglycyl]-glycine methyl ester (7e). A solution of 2naphthaldehyde (156 mg, $1.00 \mathrm{mmol})$ and methylamine $(124 \mu \mathrm{L} 1.00 \mathrm{mmol}, 33 \% \mathrm{in} \mathrm{EtOH})$ in chloroform (1.0 $\mathrm{mL}$ ) were stirred for $15 \mathrm{~min}$ before $N$-Boc-Ala-OH $(119 \mathrm{mg}, 1.20 \mathrm{mmol})$ and methyl isocyanoacetate $(90.0 \mu \mathrm{L}$, $1.00 \mathrm{mmol})$ in chloroform $(0.5 \mathrm{~mL})$ were added at $0{ }^{\circ} \mathrm{C}$. After stirring for further $30 \mathrm{~min}$, the reaction mixture was heated in a microwave $\left(30 \mathrm{~min}, 80^{\circ} \mathrm{C}, 150 \mathrm{~W}\right)$. After cooling to room temperature, the solution was worked up according to $7 \mathrm{a}$. The two diastereomeric products (1:1) could be separated by flash chromatography (silica, hexanes:ethyl acetate 1:1). Yield: $164 \mathrm{mg}(0.359 \mu \mathrm{mol}, 36 \%)$ colorless oil. Diastereomer 1: $R_{f}(7 e-1)=0.17$ (hexanes:ethyl acetate 1:1). ${ }^{1} \mathrm{H} N M R\left(C D C l_{3}, 400 \mathrm{MHz}\right): \delta=1.40(\mathrm{~d}, 3 \mathrm{H}), 1.45$ (s, $9 \mathrm{H}), 2.95(\mathrm{~s}, 3 \mathrm{H}), 3.76(\mathrm{~s}, 3 \mathrm{H}), 4.01(\mathrm{dd}, 1 \mathrm{H}), 4.21(\mathrm{dd}, 1 \mathrm{H}), 4.68(\mathrm{dq}, 1 \mathrm{H}), 5.51(\mathrm{~d}, 1 \mathrm{H}), 6.40(\mathrm{bs}, 1 \mathrm{H}), 6.53$ $(\mathrm{s}, 1 \mathrm{H}), 7.40(\mathrm{~d}, 1 \mathrm{H}), 7.49-7.55(\mathrm{~m}, 2 \mathrm{H}), 7.82-7.88(\mathrm{~m}, 3 \mathrm{H}), 7.94(\mathrm{~s}, 1 \mathrm{H}) \mathrm{ppm} .{ }^{13} \mathrm{C} \mathrm{NMR}\left(\mathrm{CDCl}_{3}, 100 \mathrm{MHz}\right): \delta=$ 18.7 (q), 28.3 (q), 32.2 (q), 41.3 (t), 46.8 (d), 52.4 (q), 60.8 (d), 79.6 (s), 126.6 (d), 126.6 (d), 126.7 (d), 127.6 (d), 128.2 (d), 128.8 (d), 129.0 (d), 131.4 (s), 133.1 (s), 133.2 (s), 169.5 (s), 169.9 (s), 171.1 (s), 174.1 (s) ppm. Diastereomer 2: $R_{f}(7 e-2)=0.12$ (hexanes:ethyl acetate 1:1). ${ }^{1} \mathrm{H} N M R\left(C D C l_{3}, 400 \mathrm{MHz}\right): \delta=1.34(\mathrm{~d}, 3 \mathrm{H}), 1.45$ $(\mathrm{s}, 9 \mathrm{H}), 2.97(\mathrm{~s}, 3 \mathrm{H}), 3.78(\mathrm{~s}, 3 \mathrm{H}), 4.07(\mathrm{dd}, 1 \mathrm{H}), 4.18(\mathrm{dd}, 1 \mathrm{H}), 4.65(\mathrm{dq}, 1 \mathrm{H}), 5.45(\mathrm{bs}, 1 \mathrm{H}), 6.51(\mathrm{~s}, 1 \mathrm{H}), 6.85$ (bs, $1 \mathrm{H}), 7.38(\mathrm{~d}, 1 \mathrm{H}), 7.49-7.55(\mathrm{~m}, 2 \mathrm{H}), 7.82-7.88(\mathrm{~m}, 3 \mathrm{H}), 7.95(\mathrm{~s}, 1 \mathrm{H}) \mathrm{ppm} .{ }^{13} \mathrm{C} \mathrm{NMR}\left(\mathrm{CDCl}_{3}, 100 \mathrm{MHz}\right): \delta$ $=18.7(q), 28.3(q), 32.2(q), 41.3(t), 46.8$ (d), $52.3(q), 60.4$ (d), 79.9 (s), 126.5 (d), 126.7 (d), 126.7 (d), 127.6 (d), 128.2 (d), 128.3 (d), 129.1 (d), 131.8 (s), 133.0 (s), 133.2 (s), 169.3 (s), 170.0 (s), 170.1 (s), 174.3 (s) ppm. HRMS (Cl) calc. for $\mathrm{C}_{24} \mathrm{H}_{32} \mathrm{~N}_{3} \mathrm{O}_{6}{ }^{+}[\mathrm{M}+\mathrm{H}]^{+}:$458.2286, found 458.2288.

$\mathbf{N}$-tert-Butoxycarbonyl-(S)-alanyl-( $\mathbf{N}$-allyl-phenylglycyl)-glycine (8a). Methyl ester 7a (1.00 g, $2.31 \mathrm{mmol})$ was dissolved in THF/MeOH $(3: 1,11.6 \mathrm{~mL})$ and a solution $\mathrm{LiOH}(58.0 \mathrm{mg}, 2.42 \mathrm{mmol})$ in $\mathrm{H}_{2} \mathrm{O}(4.6 \mathrm{~mL})$ was added. The solution was stirred overnight at room temperature before it was diluted with ethyl acetate $(20 \mathrm{~mL})$. The organic layer was washed trice with water. The combined aqueous layers were acidified with $1 \mathrm{M} \mathrm{HCl}$ and extracted trice with dichloromethane $\left(15 \mathrm{~mL}\right.$ each). The combined organic layers were dried $\left(\mathrm{Na}_{2} \mathrm{SO}_{4}\right)$ and the solvent was evaporated in vacuo providing $8 \mathrm{a}(0.87 \mathrm{~g}, 2.08 \mathrm{mmol}, 90 \%)$ as pale yellow foam and as a $1: 1$ diastereomeric mixture. $\mathrm{Mp} 60-64{ }^{\circ} \mathrm{C} . \mathrm{R}_{\mathrm{f}}(\mathbf{8 a})=0.10$ (hexanes:ethyl acetate 1:1). Diastereomer $1:{ }^{1} \mathrm{H} N M R$ $\left(\mathrm{CDCl}_{3}, 400 \mathrm{MHz}\right): \delta=1.29(\mathrm{~d}, J 6.8 \mathrm{~Hz}, 3 \mathrm{H}), 1.43(\mathrm{~s}, 9 \mathrm{H}), 3.87-4.18(\mathrm{~m}, 4 \mathrm{H}), 4.47(\mathrm{q}, J 6.8 \mathrm{~Hz}, 1 \mathrm{H}), 5.01(\mathrm{~d}, J$ $10.0 \mathrm{~Hz}, 1 \mathrm{H}$ ), 5.08 (d, J $16.6 \mathrm{~Hz}, 1 \mathrm{H}), 5.29-5.42(\mathrm{~m}, 2 \mathrm{H}), 6.02$ (s, $1 \mathrm{H}), 7.11$ (bs, $1 \mathrm{H}), 7.29-7.39$ (m, $5 \mathrm{H}) \mathrm{ppm}$. ${ }^{13} \mathrm{C} \mathrm{NMR}\left(\mathrm{CDCl}_{3}, 100 \mathrm{MHz}\right): \delta=17.9(\mathrm{q}), 28.3(\mathrm{q}), 41.5(\mathrm{t}), 46.7$ (d), $49.2(\mathrm{t}), 63.1(\mathrm{~d}), 80.3(\mathrm{~s}), 117.6(\mathrm{t}), 128.7$ 
(d), 128.8 (d), 129.4 (d), 133.2 (s), 156.1 (s), 171.8 (s), 171.9 (s) ppm. Signals of the ester and amide CO groups could not be detected. Diastereomer 2: ${ }^{1} \mathrm{H} \mathrm{NMR}\left(\mathrm{CDCl}_{3}, 400 \mathrm{MHz}\right): \delta=1.33(\mathrm{~d}, J 6.8 \mathrm{~Hz}, 3 \mathrm{H}), 1.43(\mathrm{~s}, 9 \mathrm{H})$, 3.87-4.18 (m, 4 H, 4-H), $4.62(\mathrm{~m}, 1 \mathrm{H}), 5.01(\mathrm{~d}, J 10.0 \mathrm{~Hz}, 1 \mathrm{H}), 5.08(\mathrm{~d}, J 16.6 \mathrm{~Hz}, 1 \mathrm{H}), 5.56-5.68(\mathrm{~m}, 2 \mathrm{H}), 6.10$ $(\mathrm{s}, 1 \mathrm{H}), 6.70$ (bs, $1 \mathrm{H}), 7.29-7.39(\mathrm{~m}, 5 \mathrm{H}) \mathrm{ppm} .{ }^{13} \mathrm{C} \mathrm{NMR}\left(\mathrm{CDCl}_{3}, 100 \mathrm{MHz}\right): \delta=18.8(\mathrm{q}), 28.3(\mathrm{q}), 41.6(\mathrm{t}), 46.9$ (d), 48.9 (t), 62.1 (d), 80.3 (s), 117.6 (t), 128.7 (d), 128.8 (d), 129.9 (d), 134.0 (s), 156.1 (s), 171.8 (s), 171.9 (s) ppm. Signal of the secondary amide $\mathrm{CO}$ groups could not be detected. HRMS (Cl) calc. for $\mathrm{C}_{21} \mathrm{H}_{30} \mathrm{~N}_{3} \mathrm{O}_{6}{ }^{+}[\mathrm{M}+\mathrm{H}]^{+}$: 420.2129 , found 420.2135.

\section{$\mathbf{N}$-tert-Butoxycarbonyl-(S)-alanyl-( $\mathrm{N}$-allyl-phenylglycyl)-glycine $\quad(2 S, 6 E)-10-($ allyloxy-carbonyl)-7-methyl-dec-}

6-en-2-yl ester (9a). Tripeptide 8a (252 mg, $0.60 \mathrm{mmol}$ ) and alcohol (S)-6 (159 mg, $0.66 \mathrm{mmol})$ were dissolved in dichloromethane $(4.8 \mathrm{~mL})$. After cooling to $0{ }^{\circ} \mathrm{C}$ DMAP $(7.30 \mathrm{mg}, 0.06 \mathrm{mmol})$ and $\mathrm{EDC} \cdot \mathrm{HCl}(138 \mathrm{mg}, 0.72$ $\mathrm{mmol})$ in dichloromethane $(1.8 \mathrm{~mL})$ were added. The mixture was allowed to warm to room temperature overnight before the solvent was removed in vacuo. The residue was dissolved in ether (15 $\mathrm{mL})$ and the solution washed with $1 \mathrm{~N} \mathrm{KHSO}_{4}$ and sat. $\mathrm{NaHCO}_{3}$, dried $\left(\mathrm{Na}_{2} \mathrm{SO}_{4}\right)$ and the solvent was evaporated in vacuo. Flash chromatography (silica, hexanes:ethyl acetate 6:4) provided tripeptide ester 9a (241 mg, $0.38 \mathrm{mmol}$, $63 \%)$ as a $1: 1$ diastereomeric mixture. $\mathrm{R}_{\mathrm{f}}(9 \mathrm{a})=0.34$ (hexanes:ethyl acetate 6:4). Diastereomer $1:{ }^{1} \mathrm{H} N M R$ $\left(\mathrm{CDCl}_{3}, 400 \mathrm{MHz}\right): \delta=1.23(\mathrm{~m}, 3 \mathrm{H}), 1.30(\mathrm{~d}, J 6.8 \mathrm{~Hz}, 3 \mathrm{H}), 1.33(\mathrm{~m}, 2 \mathrm{H}), 1.44(\mathrm{~s}, 9 \mathrm{H}), 1.53(\mathrm{~m}, 2 \mathrm{H}), 1.60(\mathrm{~s}, 3$ H), $1.98(\mathrm{~m}, 2 \mathrm{H}), 2.31(\mathrm{t}, J 8.0 \mathrm{~Hz}, 2 \mathrm{H}), 2.44(\mathrm{t}, J 8.3 \mathrm{~Hz}, 2 \mathrm{H}), 3.80(\mathrm{dd}, J 17.6,4.5 \mathrm{~Hz}, 1 \mathrm{H}), 4.03(\mathrm{~m}, 2 \mathrm{H}), 4.25$ $(\mathrm{dd}, J$ 18.1, $6.0 \mathrm{~Hz}, 1 \mathrm{H}), 4.44(\mathrm{~m}, 1 \mathrm{H}), 4.59(\mathrm{~m}, 2 \mathrm{H}), 4.91-5.19(\mathrm{~m}, 5 \mathrm{H}), 5.23(\mathrm{~d}, J 10.3 \mathrm{~Hz}, 1 \mathrm{H}), 5.32(\mathrm{dd}, J 17.0$, $0.8 \mathrm{~Hz}, 1 \mathrm{H}), 5.91(\mathrm{~m}, 1 \mathrm{H}), 6.05(\mathrm{~s}, 1 \mathrm{H}), 7.04(\mathrm{~m}, 1 \mathrm{H}), 7.32-7.44(\mathrm{~m}, 5 \mathrm{H}) \mathrm{ppm} .{ }^{13} \mathrm{C} \mathrm{NMR}\left(\mathrm{CDCl}_{3}, 100 \mathrm{MHz}\right): \delta=$ $15.9(q), 18.1(q), 19.9(q), 25.3(t), 27.5(t), 28.3(q), 33.1(t), 34.6(t), 35.3(t), 41.7(t), 46.7(d), 48.9(t), 62.7$ $(\mathrm{d}), 65.0(\mathrm{t}), 72.6(\mathrm{~d}), 80.1(\mathrm{~s}), 117.3(\mathrm{t}), 118.1(\mathrm{t}), 124.8(\mathrm{~d}), 128.7(\mathrm{~d}), 128.8(\mathrm{~d}), 129.7(\mathrm{~d}), 129.7(\mathrm{~s}), 132.3(\mathrm{~d})$, 133.8 (s), 156.0 (s), 169.4 (s), 170.8 (s), 173.0 (s) ppm. Diastereomer $2:{ }^{1} \mathrm{H} \mathrm{NMR}\left(\mathrm{CDCl}_{3}, 400 \mathrm{MHz}\right): \delta=1.23$ (m, $3 \mathrm{H}), 1.36(\mathrm{~d}, J 6.8 \mathrm{~Hz}, 3 \mathrm{H}), 1.33(\mathrm{~m}, 2 \mathrm{H}), 1.44(\mathrm{~s}, 9 \mathrm{H}), 1.53(\mathrm{~m}, 2 \mathrm{H}), 1.60(\mathrm{~s}, 3 \mathrm{H}), 1.98(\mathrm{~m}, 2 \mathrm{H}), 2.31(\mathrm{t}, J 8.0$ $\mathrm{Hz}, 2 \mathrm{H}), 2.44(\mathrm{t}, J 8.3 \mathrm{~Hz}, 2 \mathrm{H}), 3.80(\mathrm{dd}, J 17.6,4.5 \mathrm{~Hz}, 1 \mathrm{H}), 4.03(\mathrm{~m}, 2 \mathrm{H}), 4.25(\mathrm{dd}, J 18.1,6.0 \mathrm{~Hz}, 1 \mathrm{H}), 4.59(\mathrm{~m}$, $2 \mathrm{H}), 4.61(\mathrm{~m}, 1 \mathrm{H}), 4.91-5.19(\mathrm{~m}, 5 \mathrm{H}), 5.23(\mathrm{~d}, J$ 10.3, $1 \mathrm{H}), 5.32(\mathrm{dd}, J$ 17.0, $0.8 \mathrm{~Hz}, 1 \mathrm{H}), 5.91(\mathrm{~m}, 1 \mathrm{H}), 6.11(\mathrm{~s}$, $1 \mathrm{H}), 7.04(\mathrm{~m}, 1 \mathrm{H}), 7.32-7.44(\mathrm{~m}, 5 \mathrm{H}) \mathrm{ppm} .{ }^{13} \mathrm{C} \mathrm{NMR}\left(\mathrm{CDCl}_{3}, 100 \mathrm{MHz}\right): \delta=15.9(\mathrm{q}), 18.1(\mathrm{q}), 19.9(\mathrm{q}), 25.4(\mathrm{t})$, $27.6(t), 28.3(q), 33.1(t), 34.6(t), 35.4(t), 41.6(t), 46.7(d), 48.9(t), 62.7(d), 65.0(t), 72.4(d), 80.1(s), 117.3$ (t), 118.1 (t), 124.9 (d), 128.7 (d), 128.8 (d), 129.7 (d), 129.7 (s), 132.3 (2 d, C-5), 133.8 (s), 156.0 (s), 169.4 (s), 170.8 (s), 173.0 (s) ppm. HRMS (Cl) calc. for $\mathrm{C}_{35} \mathrm{H}_{52} \mathrm{~N}_{3} \mathrm{O}_{8}{ }^{+}[\mathrm{M}+\mathrm{H}]^{+}: 642.3749$, found 642.3751 .

\section{$N$-tert-Butoxycarbonyl-(S)-alanyl-( $N$-allyl-phenylglycyl)-glycine $\quad(2 S, 6 E)-10$-carboxy-7-methyl-dec-6-en-2-yl} ester (10a). Allylester 9a (205 mg, $0.32 \mathrm{mmol})$ was dissolved in THF $(6.4 \mathrm{~mL})$ under $\mathrm{N}_{2}$, before $\left.\mathrm{Pd}_{(\mathrm{PPh}}\right)_{4}(37.0$ $\mathrm{mg}, 0.032 \mathrm{mmol}$ ) and morpholine $(55.4 \mu \mathrm{L}, 0.64 \mathrm{mmol})$ were added. The solution was stirred overnight at room temperature, before it was diluted with ethyl acetate $(20 \mathrm{~mL})$. The solution was washed with $\mathrm{H}_{2} \mathrm{O}$ and brine $\left(20 \mathrm{~mL}\right.$ each), dried $\left(\mathrm{Na}_{2} \mathrm{SO}_{4}\right)$ and the solvent was evaporated in vacuo providing 10a (115 mg, 0.19 $\mathrm{mmol}, 60 \%)$ as a pale yellow resin. Diastereomeric ratio: 1:1. $R_{f}(\mathbf{1 0 a})=0.21$ (hexanes:ethyl acetate $1: 1$ ). Diastereomer 1: ${ }^{1} \mathrm{H} \mathrm{NMR}\left(\mathrm{CDCl}_{3}, 400 \mathrm{MHz}\right): \delta=1.21(\mathrm{~m}, 3 \mathrm{H}), 1.35(\mathrm{~d}, J 6.8 \mathrm{~Hz}, 3 \mathrm{H}), 1.33(\mathrm{~m}, 2 \mathrm{H}), 1.44(\mathrm{~s}, 9 \mathrm{H})$, $1.53(\mathrm{~m}, 2 \mathrm{H}), 1.61(\mathrm{~s}, 3 \mathrm{H}), 1.98(\mathrm{td}, J 6.8,6.8 \mathrm{~Hz}, 2 \mathrm{H}), 2.31(\mathrm{t}, J 6.8 \mathrm{~Hz}, 2 \mathrm{H}), 2.45(\mathrm{t}, J 7.0 \mathrm{~Hz}, 2 \mathrm{H}), 3.80-4.11$ $(\mathrm{m}, 4 \mathrm{H}), 4.47(\mathrm{qd}, J 6.8,6.8 \mathrm{~Hz}, 1 \mathrm{H}), 4.94-5.09(\mathrm{~m}, 4 \mathrm{H}), 5.16(\mathrm{tq}, J 6.3,0.8 \mathrm{~Hz}, 1 \mathrm{H}), 5.62(\mathrm{~m}, 1 \mathrm{H}), 6.13(\mathrm{~s}, 1 \mathrm{H})$,

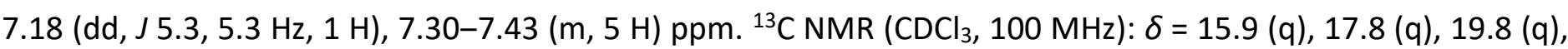
$25.1(\mathrm{t}), 27.1(\mathrm{t}), 28.3(\mathrm{q}), 33.5(\mathrm{t}), 34.5(\mathrm{t}), 34.7(\mathrm{t}), 41.8(\mathrm{t}), 46.8(\mathrm{~d}), 48.8(\mathrm{t}), 62.8(\mathrm{~d}), 72.5(\mathrm{~d}), 81.3(\mathrm{~s}), 117.5$ (t), 125.2 (d), 128.5 (d), 128.7 (d), 128.8 (d), 129.6 (s), 130.0 (d), 133.6 (s), 156.6 (s), 169.2 (s), 169.6 (s), 173.6 (s), 174.6 (s) ppm. Diastereomer 2: ${ }^{1} \mathrm{H} N M R\left(\mathrm{CDCl}_{3}, 400 \mathrm{MHz}\right): \delta=1.21(\mathrm{~m}, 3 \mathrm{H}), 1.30(\mathrm{~d}, J 6.5 \mathrm{~Hz}, 3 \mathrm{H}), 1.33(\mathrm{~m}$, $2 \mathrm{H}), 1.43(\mathrm{~s}, 9 \mathrm{H}), 1.53(\mathrm{~m}, 2 \mathrm{H}), 1.61(\mathrm{~s}, 3 \mathrm{H}), 1.98(\mathrm{td}, J 6.8,6.8 \mathrm{~Hz}, 2 \mathrm{H}), 2.31(\mathrm{t}, J 6.8 \mathrm{~Hz}, 2 \mathrm{H}), 2.45(\mathrm{t}, J 7.0 \mathrm{~Hz}$, $2 \mathrm{H}), 3.80-4.11(\mathrm{~m}, 4 \mathrm{H}, 4-\mathrm{H}), 4.61(\mathrm{qd}, J \mathrm{~J} .3,7.3 \mathrm{~Hz}, 1 \mathrm{H}), 4.94-5.09(\mathrm{~m}, 4 \mathrm{H}), 5.16(\mathrm{tq}, J$ 6.3, $0.8 \mathrm{~Hz}, 1 \mathrm{H}), 5.49$ 
$(\mathrm{d}, J 8.5 \mathrm{~Hz}, 1 \mathrm{H}), 6.10(\mathrm{~s}, 1 \mathrm{H}), 6.68(\mathrm{dd}, J 5.3,5.3 \mathrm{~Hz}, 1 \mathrm{H}), 7.30-7.43(\mathrm{~m}, 5 \mathrm{H}) \mathrm{ppm} .{ }^{13} \mathrm{C} \mathrm{NMR}\left(\mathrm{CDCl}_{3}, 100 \mathrm{MHz}\right)$ : $\delta=16.0(\mathrm{q}), 17.8(\mathrm{q}), 19.6(\mathrm{q}), 25.1(\mathrm{t}), 27.1(\mathrm{t}), 28.3(\mathrm{q}), 33.5(\mathrm{t}), 34.5(\mathrm{t}), 34.7(\mathrm{t}), 41.8(\mathrm{t}), 46.8(\mathrm{~d}), 48.8(\mathrm{t})$, 62.8 (d), 72.4 (d), 81.3 (s), 117.5 (t), 125.2 (d), 128.5 (d), 128.7 (d), 128.9 (d), 129.6 (s), 130.0 (d), 133.6 (s), 156.6 (s), 169.2 (s), 169.6 (s), 173.6 (s), 174.6 (s) ppm. HRMS (Cl) calc. for $\mathrm{C}_{37} \mathrm{H}_{48} \mathrm{~N}_{3} \mathrm{O}_{8}{ }^{+}[\mathrm{M}+\mathrm{H}]^{+}$: 602.3436, found 602.3472.

\section{(9S,19S,14E)-6-Phenyl-7-allyl-9,14,19-trimethyl-1-oxa-4,7,10-triazacylononadec-14-en-2,5,8,11-tetraon}

(11a). Acid 10a (109.4 mg, $0.18 \mathrm{mmol}$ ) and pentafluorophenol $(36.8 \mathrm{mg}, 0.20 \mathrm{mmol}$ ) were dissolved in dichloromethane $(1.8 \mathrm{~mL})$ and the solution was cooled to $0{ }^{\circ} \mathrm{C}$ before $\mathrm{EDC} \cdot \mathrm{HCl}(38.3 \mathrm{mg}, 0.20 \mathrm{mmol})$ was added. The reaction mixture was warmed to room temperature overnight, diluted with ethyl acetate $(20 \mathrm{~mL})$ and washed with sat. $\mathrm{NaHCO}_{3}$. After drying $\left(\mathrm{Na}_{2} \mathrm{SO}_{4}\right)$ and evaporation of the solvent the crude active ester was dissolved in dichloromethane/trifluoroacetic acid 4:1 $(2 \mathrm{~mL})$ and the reaction was monitored by TLC. After Boc cleavage was complete, the solution was diluted with dichloromethane $(2.7 \mathrm{~mL})$ and was added dropwise to a suspension $(80 \mathrm{~mL})$ of chloroform/sat. $\mathrm{NaHCO}_{3}(7: 1)$ at $40{ }^{\circ} \mathrm{C}$. The solution was warmed up to $60{ }^{\circ} \mathrm{C}$ overnight, before it was diluted with $\mathrm{H}_{2} \mathrm{O}(50 \mathrm{~mL})$. The phases were separated and the aqueous layer was washed trice with dichloromethane. The combined organic layers were dried $\left(\mathrm{Na}_{2} \mathrm{SO}_{4}\right)$ and the solvent was evaporated in vacuo. The crude product was purified by flash chromatography (silica, hexanes:ethyl acetate 3:7) to give miuraenamide derivative $11 \mathrm{a}(35.7 \mathrm{mg}, 73.8 \mu \mathrm{mol}, 41 \%)$ as a colorless foam and as an inseparable 1:1 diastereomeric mixture. $R_{f}(\mathbf{1 1 a})=0.23$ (hexanes:ethyl acetate 3:7). Diastereomer $1:{ }^{1} \mathrm{H} N \mathrm{NR}\left(\mathrm{CDCl}_{3}, 400\right.$ $\mathrm{MHz}): \delta=1.23(\mathrm{~m}, 3 \mathrm{H}), 1.31(\mathrm{~d}, J 6.5 \mathrm{~Hz}, 1 \mathrm{H}), 1.39(\mathrm{~m}, 2 \mathrm{H}), 1.53(\mathrm{~m}, 2 \mathrm{H}), 1.66(\mathrm{~s}, 3 \mathrm{H}), 2.01(\mathrm{~m}, 2 \mathrm{H})$, 2.27-2.49 (m, $4 \mathrm{H}), 3.88$ (dd, J 17.3, $5.5 \mathrm{~Hz}, 1 \mathrm{H}), 3.91-4.17(\mathrm{~m}, 3 \mathrm{H}), 4.77-5.01(\mathrm{~m}, 3 \mathrm{H}), 5.03(\mathrm{~s}, 1 \mathrm{H}), 5.15\left(\mathrm{~d}, J_{5}\right.$ $=17.3 \mathrm{~Hz}, 1 \mathrm{H}), 5.23(\mathrm{~d}, J 10.0 \mathrm{~Hz}, 1 \mathrm{H}), 5.74(\mathrm{~m}, 1 \mathrm{H}), 6.59-6.78(\mathrm{~m}, 2 \mathrm{H}), 7.33-7.40(\mathrm{~m}, 5 \mathrm{H}) \mathrm{ppm} .{ }^{13} \mathrm{C} \mathrm{NMR}$ $\left(\mathrm{CDCl}_{3}, 100 \mathrm{MHz}\right): \delta=15.8(\mathrm{q}), 18.2(\mathrm{q}), 19.9(\mathrm{q}), 23.4(\mathrm{t}), 27.0(\mathrm{t}), 33.3(\mathrm{t}), 34.4(\mathrm{t}), 35.3(\mathrm{t}), 42.6(\mathrm{t}), 47.2(\mathrm{~d})$, $49.7(t), 63.4$ (d), 72.7 (d), 119.2 (t), 126.0 (d), 126.3 (d), 128.8 (d), 129.2 (d), 129.9 (s), 131.3 (d), $133.6(\mathrm{~s})$, 167.6 (s), 168.9 (s), 169.2 (s), 172.4 (s) ppm. Diastereomer 2: ${ }^{1} \mathrm{H} \mathrm{NMR}\left(\mathrm{CDCl}_{3}, 400 \mathrm{MHz}\right): \delta=1.23(\mathrm{~m}, 3 \mathrm{H}), 1.34$ (d, J $6.5 \mathrm{~Hz}, 3 \mathrm{H}), 1.39(\mathrm{~m}, 2 \mathrm{H}), 1.53(\mathrm{~m}, 2 \mathrm{H}), 1.66(\mathrm{~s}, 3 \mathrm{H}), 2.01(\mathrm{~m}, 2 \mathrm{H}), 2.27-2.49(\mathrm{~m}, 4 \mathrm{H}), 4.23(\mathrm{dd}, J 17.8$, $6.8 \mathrm{~Hz}, 1 \mathrm{H}), 3.91-4.17(\mathrm{~m}, 3 \mathrm{H}), 5.28-5.43(\mathrm{~m}, 3 \mathrm{H}), 5.03(\mathrm{~s}, 1 \mathrm{H}), 5.39(\mathrm{~m}, 2 \mathrm{H}), 5.74(\mathrm{~m}, 1 \mathrm{H}), 6.22(\mathrm{~m}, 1 \mathrm{H})$, $6.70(\mathrm{~m}, 1 \mathrm{H}), 7.33-7.40(\mathrm{~m}, 5 \mathrm{H}) \mathrm{ppm} .{ }^{13} \mathrm{C} \mathrm{NMR}\left(\mathrm{CDCl}_{3}, 100 \mathrm{MHz}\right): \delta=16.2(\mathrm{q}), 18.8(\mathrm{q}), 19.9(\mathrm{q}), 23.4(\mathrm{t}), 27.0$ $(\mathrm{t}), 32.8(\mathrm{t}), 35.4(\mathrm{t}), 35.2(\mathrm{t}), 42.2(\mathrm{t}), 47.2(\mathrm{~d}), 49.7(\mathrm{t}), 63.4(\mathrm{~d}), 71.8(\mathrm{~d}), 119.2(\mathrm{t}), 126.0(\mathrm{~d}), 126.3(\mathrm{~d}), 128.8$ (d), 129.2 (d), 129.9 (s), 131.3 (d), 133.3 (s), 167.2 (s), 168.9 (s), 169.2 (s), 172.6 (s) ppm. HRMS (Cl) calc. for $\mathrm{C}_{27} \mathrm{H}_{38} \mathrm{~N}_{3} \mathrm{O}_{5}{ }^{+}[\mathrm{M}+\mathrm{H}]^{+}:$484.2806, found 484.2809.

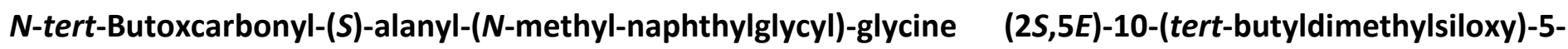
methyl-dec-5-en-2-yl ester (12e). According to 8a methyl ester 7e (251 mg, $0.57 \mathrm{mmol})$ in THF/MeOH (3:1, 2.8 $\mathrm{mL}$ ) was saponified with a solution of $\mathrm{LiOH}(25.7 \mathrm{mg}, 0.60 \mathrm{mmol})$ in $\mathrm{H}_{2} \mathrm{O}(1.9 \mathrm{~mL})$. The crude acid (dr 1:1) was directly used without further purification. For that, the acid (253 mg, $570 \mu \mathrm{mol}$ ) and alcohol (S)-2 (204 mg, $0.68 \mathrm{mmol}$ ) were dissolved in dichloromethane $\left(4.6 \mathrm{~mL}\right.$ ) and the solution was cooled to $0{ }^{\circ} \mathrm{C}$ before DCC (140 $\mathrm{mg}, 0.68 \mathrm{mmol})$ and DMAP $(83.1 \mathrm{mg}, 0.68 \mathrm{mmol})$ in dichloromethane $(1.7 \mathrm{~mL})$ were added. The reaction mixture was warmed to room temperature overnight, diluted with ethyl acetate $(20 \mathrm{~mL})$ and washed with sat. $\mathrm{NaHCO}_{3}$ and $1 \mathrm{~N} \mathrm{KHSO}_{4}$, dried $\left(\mathrm{Na}_{2} \mathrm{SO}_{4}\right)$ and the solvent was evaporated in vacuo. Flash chromatography (silica, hexanes:ethyl acetate 6:4) provided tripeptide ester $12 \mathrm{e}(305 \mathrm{mg}, 0.42 \mathrm{mmol}, 74 \%)$ as a 1:1 diastereomeric mixture. In addition, alcohol $(S)-2(72.3 \mathrm{mg}, 0.24 \mathrm{mmol}, 35 \%)$ could be recovered. $\mathrm{R}_{\mathrm{f}}(\mathbf{1 2 e})=0.23$ (hexanes:ethyl acetate 6:4). Diastereomer 1: ${ }^{1} \mathrm{H} \mathrm{NMR}\left(400 \mathrm{MHz}, \mathrm{CDCl}_{3}\right): \delta=0.05(\mathrm{~s}, 6 \mathrm{H}), 0.89(\mathrm{~s}, 9 \mathrm{H}), 1.26(\mathrm{~d}$, $3 \mathrm{H}), 1.34(\mathrm{~d}, 3 \mathrm{H}), 1.42(\mathrm{~m}, 2 \mathrm{H}), 1.45(\mathrm{~s}, 9 \mathrm{H}), 1.51(\mathrm{~m}, 2 \mathrm{H}), 1.58(\mathrm{~s}, 3 \mathrm{H}), 1.67(\mathrm{~m}, 2 \mathrm{H}), 1.94-2.03(\mathrm{~m}, 4 \mathrm{H})$, $2.95(\mathrm{~s}, 3 \mathrm{H}), 3.59(\mathrm{~m}, 2 \mathrm{H}), 4.02(\mathrm{~m}, 1 \mathrm{H}), 4.18(\mathrm{~m}, 1 \mathrm{H}), 4.67(\mathrm{dq}, 1 \mathrm{H}), 4.95(\mathrm{tq}, 1 \mathrm{H}), 5.12(\mathrm{~m}, 1 \mathrm{H}), 5.47(\mathrm{~m}, 1$ $\mathrm{H}), 6.25(\mathrm{~m}, 1 \mathrm{H}), 6.50(\mathrm{~s}, 1 \mathrm{H}), 7.40(\mathrm{~m}, 1 \mathrm{H}), 7.49-7.56(\mathrm{~m}, 2 \mathrm{H}), 7.81-7.90(\mathrm{~m}, 3 \mathrm{H}), 7.95(\mathrm{~s}, 1 \mathrm{H},) \mathrm{ppm} .{ }^{13} \mathrm{C}$ 
NMR (100 MHz, CDCl $): \delta=-5.3(q), 15.9(q), 18.3(q), 18.4(q), 19.9(q), 26.0(t), 26.0(q), 27.7(t), 28.4(q)$ ), $32.2(\mathrm{t}), 32.5(\mathrm{q}), 34.1(\mathrm{t}), 35.4(\mathrm{t}), 41.6(\mathrm{t}), 46.8(\mathrm{~d}), 60.9(\mathrm{~d}), 63.2(\mathrm{t}), 69.7(\mathrm{t}), 72.6(\mathrm{~d}), 78.3(\mathrm{~s}), 125.2(\mathrm{~d}), 126.7$ (d), 127.6 (d), 128.2 (d), 128.7 (s), 129.1 (s), 131.1 (s), 133.2 (s), 169.1 (s), 171.8 (s), 171.8 (s) ppm. Diastereomer 2 (selected signals): ${ }^{1} \mathrm{H}$ NMR $\left(400 \mathrm{MHz}, \mathrm{CDCl}_{3}\right): \delta=0.06(\mathrm{~s}, 6 \mathrm{H}), 0.90(\mathrm{~s}, 9 \mathrm{H}), 1.25(\mathrm{~d}, 3 \mathrm{H}), 1.59$ $(\mathrm{s}, 3 \mathrm{H}), 2.98(\mathrm{~s}, 3 \mathrm{H}), 6.53(\mathrm{~s}, 1 \mathrm{H}), 6.73(\mathrm{~m}, 1 \mathrm{H})$ ppm. HRMS (Cl) calc. for $\mathrm{C}_{40} \mathrm{H}_{66} \mathrm{~N}_{3} \mathrm{O}_{7} \mathrm{Si}^{2+}[\mathrm{M}+\mathrm{H}]^{+}:$727.4581, found 727.4593 .

\section{$\mathbf{N}$-tert-Butoxcarbonyl-(S)-alanyl-( $N$-methyl-naphthylglycyl)-glycine (2S,5E)-10-carboxy-5-methyl-dec-5-en-2-} yl ester (13e): Silylester 12e (337 mg, $0.460 \mathrm{mmol})$ was dissolved in THF (1.4 mL) before TBAF·3 $\mathrm{H}_{2} \mathrm{O}(163 \mathrm{mg}$ $0.510 \mathrm{mmol})$ in $\mathrm{H}_{2} \mathrm{O}(1.0 \mathrm{~mL})$ was added. The reaction was monitored by TLC and after completion aqueous workup provided the corresponding alcohol which was directly subjected to Jones oxidation. For that, the alcohol (234 mg, $0.380 \mathrm{mmol})$ was dissolved in acetone $(2.7 \mathrm{~mL})$ before Jones reagent $(3 \mathrm{M}, 380 \mu \mathrm{L}, 1.14 \mathrm{mmol})$ was added at $0{ }^{\circ} \mathrm{C}$. Stirring was continued for 20 min before $\mathrm{H}_{2} \mathrm{O}(5 \mathrm{~mL})$ was added. Ethyl acetate was added and the aqueous layer was extracted twice with ethyl acetate. The combined organic layers were dried $\left(\mathrm{Na}_{2} \mathrm{SO}_{4}\right)$ and the solvent was evaporated in vacuo. Flash chromatography (silica, hexanes:ethyl acetate 1:1+ $1 \% \mathrm{AcOH})$ provided acid $13 \mathrm{e}(162 \mathrm{mg}, 0.259 \mathrm{mmol}, 68 \%)$ as a 58:42 diastereomeric mixture. $\mathrm{R}_{\mathrm{f}}(\mathbf{1 3 e - 1})=0.36$, $R_{f}(13 e-2)=0.31$ (hexanes:ethyl acetate $\left.1: 1+1 \% \mathrm{AcOH}\right)$. Diastereomer $1:{ }^{1} \mathrm{H}$ NMR $\left(400 \mathrm{MHz}, \mathrm{CDCl}_{3}\right): \delta=1.24$ $(\mathrm{m}, 3 \mathrm{H}), 1.31(\mathrm{~d}, 3 \mathrm{H}), 1.44(\mathrm{~s}, 9 \mathrm{H}), 1.57(\mathrm{~s}, 3 \mathrm{H}), 1.59-1.78(\mathrm{~m}, 4 \mathrm{H}), 1.96-2.07(\mathrm{~m}, 4 \mathrm{H}), 2.28(\mathrm{~m}, 2 \mathrm{H}), 2.95(\mathrm{~s}$, $3 \mathrm{H}), 3.97(\mathrm{~m}, 1 \mathrm{H}), 4.16(\mathrm{dd}, 1 \mathrm{H}), 4.70(\mathrm{~m}, 1 \mathrm{H}), 4.92(\mathrm{~m}, 1 \mathrm{H}), 5.08(\mathrm{t}, 1 \mathrm{H}), 5.71(\mathrm{~d}, 1 \mathrm{H}), 6.55(\mathrm{~s}, 1 \mathrm{H}), 7.14(\mathrm{~m}$, $1 \mathrm{H}), 7.37(\mathrm{~d}, 1 \mathrm{H}), 7.46-7.54(\mathrm{~m}, 2 \mathrm{H}), 7.78-7.89(\mathrm{~m}, 3 \mathrm{H}), 7.92(\mathrm{~s}, 1 \mathrm{H}) \mathrm{ppm} .{ }^{13} \mathrm{C} \mathrm{NMR}\left(100 \mathrm{MHz}, \mathrm{CDCl}_{3}\right): \delta=$ $15.8(q), 18.2(q), 20.0(q), 24.6(t), 27.0(t), 28.3(q), 32.4(q), 32.4(t), 33.3(t), 35.4(t), 41.5(t), 46.9(d), 61.2$ (d), 72.1 (d), 79.6 (s), 124.1 (d), 126.5 (d), 126.5 (d), 126.5 (d), 127.6 (d), 127.6 (d), 127.6 (d), 128.2 (d), 128.5 (s), 129.0 (s), 133.1 (s), 134.9 (s), 155.2 (s), 169.1 (s), 169.3 (s), 174.4 (s), 177.9 (s) ppm. Diastereomer 2 (selected signals): ${ }^{1} \mathrm{H}$ NMR $\left(400 \mathrm{MHz}, \mathrm{CDCl}_{3}\right): \delta=1.39(\mathrm{~d}, 3 \mathrm{H}), 1.56(\mathrm{~s}, 3 \mathrm{H}), 2.26(\mathrm{~m}, 2 \mathrm{H}), 3.92(\mathrm{~m}, 1 \mathrm{H}), 4.22$ $(\mathrm{m}, 1 \mathrm{H}), 5.07(\mathrm{t}, 1 \mathrm{H}), 5.65(\mathrm{~m}, 1 \mathrm{H}), 6.51(\mathrm{~s}, 1 \mathrm{H}), 6.65(\mathrm{~m}, 1 \mathrm{H}), 7.39(\mathrm{~d}, 1 \mathrm{H}) \mathrm{ppm} .{ }^{13} \mathrm{C} \mathrm{NMR}\left(100 \mathrm{MHz} \mathrm{CDCl}_{3}\right): \delta$ $=15.7(\mathrm{q}), 18.4(\mathrm{q}), 20.1(\mathrm{q}), 24.7(\mathrm{t}), 27.1(\mathrm{t}), 33.2(\mathrm{t}), 41.6(\mathrm{t}), 60.8(\mathrm{~d}), 72.3(\mathrm{~d}), 80.0(\mathrm{~s}), 124.0(\mathrm{~d}), 126.4(\mathrm{~d})$, 126.7 (d), 126.7 (d), 127.5 (d), 127.5 (d, 127.5 (d), 128.7 (s), 128.9 (s), 133.1 (s), 134.8 (s), 155.7 (s), 169.2 (s), 169.5 (s), 169.5 (s) 177.9 (s) ppm.

\section{(9S,19S,5E)-6-(Naphthalene-2-yl)-7,9,16,19-tetramethyl-1-oxa-4,7,10-triazacyclononadec-15-en-2,5,8,11-}

tetraon (14e). According to 11a acid 13e (162 mg, $259 \mu \mathrm{mol})$ and pentafluorophenol $(52.4 \mathrm{mg}, 285 \mu \mathrm{mol})$ in dichloromethane $(2.6 \mathrm{~mL})$ were reacted with $\mathrm{EDC} \cdot \mathrm{HCl}(54.6 \mathrm{mg}, 285 \mu \mathrm{mol})$. After workup as usual the pentafluorophenyl ester obtained was dissolved in dichloromethane $(2.1 \mathrm{~mL})$ before trifluoroacetic acid $(0.50$ $\mathrm{mL}$ ) was added. After complete deprotection dichloromethane $(1 \mathrm{~mL})$ was added and the solution was added dropwise to a 7:1 suspension $\mathrm{CHCl}_{3} /$ sat. $\mathrm{NaHCO}_{3}(104 \mathrm{~mL})$ over a period of $60 \mathrm{~min}$ at $40{ }^{\circ} \mathrm{C}$. Workup as usual and flash chromatography (silica, hexanes:ethyl acetate 1:1, 4:6, 3:7) provided cyclic peptide 14 e (59.9 mg, $118 \mu \mathrm{mol}, 46 \%)$ as a colorless foam and a 78:22 diastereomeric mixture. $R_{f}(14 e-1)=0.21, R_{f}(14 e-2)=0.17$ (hexanes:ethyl acetate 3:7). Diastereomer 1: ${ }^{1} \mathrm{H}$ NMR $\left(500 \mathrm{MHz}, \mathrm{CDCl}_{3}\right): \delta=1.28(\mathrm{~d}, 3 \mathrm{H}), 1.43(\mathrm{~d}, 3 \mathrm{H}), 1.61(\mathrm{~s}$, $3 \mathrm{H}), 1.63-1.89(\mathrm{~m}, 4 \mathrm{H}), 1.93-2.16(\mathrm{~m}, 4 \mathrm{H}), 2.22(\mathrm{~m}, 2 \mathrm{H}), 2.86(\mathrm{~s}, 3 \mathrm{H}), 3.62(\mathrm{dd}, 1 \mathrm{H}), 4.46(\mathrm{dd}, 1 \mathrm{H}), 4.94-5.01$ $(\mathrm{m}, 2 \mathrm{H}), 5.11(\mathrm{t}, 1 \mathrm{H}), 6.54(\mathrm{~s}, 1 \mathrm{H}), 6.88(\mathrm{~d}, 1 \mathrm{H}), 7.01(\mathrm{~m}, 1 \mathrm{H}), 7.42(\mathrm{~d}, 1 \mathrm{H}), 7.46-7.54(\mathrm{~m}, 2 \mathrm{H}), 7.81-7.89(\mathrm{~m}, 3$ $\mathrm{H}), 8.10(\mathrm{~s}, 1 \mathrm{H}) \mathrm{ppm} .{ }^{13} \mathrm{C} \mathrm{NMR}\left(125 \mathrm{MHz}, \mathrm{CDCl}_{3}\right): \delta=15.8(\mathrm{q}), 17.6(\mathrm{q}), 19.6(\mathrm{q}), 25.5(\mathrm{t}), 26.2(\mathrm{t}), 31.5(\mathrm{q}), 32.9$ $(t), 34.6(t), 35.2(t), 41.2(t), 46.0(d), 59.3(d), 71.4(d), 125.3(d), 126.3(d), 126.4(d), 126.5(d), 127.5(d)$, 128.3 (d), 128.4 (d), 128.9 (d), 130.7 (s), 132.9 (s), 133.1 (s), 134.4 (s), 169.2 (s), 169.9 (s), 173.1 (s), 173.5 (s). Diastereomer 2 (selected signals): ${ }^{1} \mathrm{H}$ NMR $\left(500 \mathrm{MHz}, \mathrm{CDCl}_{3}\right): \delta=1.26(\mathrm{~d}, 3 \mathrm{H}), 1.57(\mathrm{~m}, 3 \mathrm{H}), 2.91(\mathrm{~s}, 3 \mathrm{H}), 4.05$ $(\mathrm{m}, 1 \mathrm{H}), 6.88(\mathrm{~d}, 1 \mathrm{H}), 7.36(\mathrm{~m}, 1 \mathrm{H})$. HRMS $(\mathrm{Cl})$ calc. for $\mathrm{C}_{29} \mathrm{H}_{38} \mathrm{~N}_{3} \mathrm{O}_{5}{ }^{+}[\mathrm{M}+\mathrm{H}]^{+}$: 508.2806, found 508.2829. 
(9S,19S,5E)-6-(4-Hydroxy-3-chlorophenyl)-7,9,16,19-tetramethyl-1-oxa-4,7,10-triazacyclononadec-15-en-

2,5,8,11-tetraon (15d). The allyl protected cyclopeptide 14d (17.0 mg, $31.0 \mu \mathrm{mol})$ was dissolved in dry $\mathrm{MeOH}$ $(0.5 \mathrm{~mL})$. Quinaldic acid $(0.5 \mathrm{mg}, 3.10 \mu \mathrm{mol}$ ) ) as well as Ru-catalyst $(1.4 \mathrm{mg}, 3.10 \mu \mathrm{mol})$ were added at room temperature. After complete deprotection (LC-MS-control), DMSO ( $23 \mu \mathrm{L}, 330 \mu \mathrm{mol}$ ) was added and the solution was stirred overnight. The solvent was evaporated in vacuo and the crude product was purified by flash chromatography (silica gel, $\mathrm{CH}_{2} \mathrm{Cl}_{2} / \mathrm{Et}_{2} \mathrm{O}$ 1:1). Miureanamide derivative 15d (12.0 mg, $23.6 \mu \mathrm{mol}, 76 \%$ ) was obtained as a 1:1 diastereomeric mixture. $R_{f}(\mathbf{1 5 d})=0.10$ (dichloromethane/Et ${ }_{2} \mathrm{O} 1: 1$ ). Diastereomer $1:{ }^{1} \mathrm{H}$ NMR $\left(500 \mathrm{MHz}_{\mathrm{CDCl}}\right.$ ): $\delta=1.28(\mathrm{~d}, J 7.3 \mathrm{~Hz}, 3 \mathrm{H}), 1.38(\mathrm{~d}, J 6.7 \mathrm{~Hz}, 3 \mathrm{H}), 1.42-1.75(\mathrm{~m}, 4 \mathrm{H}), 1.58(\mathrm{~s}, 3 \mathrm{H}), 1.96-$ $2.28(\mathrm{~m}, 6 \mathrm{H}), 2.84(\mathrm{~s}, 3 \mathrm{H}), 4.09(\mathrm{~m}, 1 \mathrm{H}), 4.67(\mathrm{~m}, 2 \mathrm{H}), 5.05-5.18(\mathrm{~m}, 4 \mathrm{H}, 1-\mathrm{H}), 6.32(\mathrm{~s}, 1 \mathrm{H}), 6.97(\mathrm{~m}, 1 \mathrm{H}), 7.16$ $(\mathrm{m}, 1 \mathrm{H}), 7.34(\mathrm{~m}, 1 \mathrm{H}), 7.42(\mathrm{~m}, 1 \mathrm{H}) .{ }^{13} \mathrm{C} \mathrm{NMR}\left(125 \mathrm{MHz}, \mathrm{CDCl}_{3}\right): \delta=15.5(\mathrm{q}), 16.4(\mathrm{q}), 20.0(\mathrm{q}), 25.6(\mathrm{t}), 26.2$ $(\mathrm{t}), 29.7(\mathrm{q}), 32.0(\mathrm{t}), 34.8(\mathrm{t}), 34.9(\mathrm{t}), 41.4(\mathrm{t}), 46.0(\mathrm{~d}), 60.4(\mathrm{~d}), 72.4(\mathrm{~d}), 116.5(\mathrm{~d}), 120.2(\mathrm{~s}), 125.2(\mathrm{~d}), 128.1$ (d), $130.2(\mathrm{~s}), 131.0(\mathrm{~s}), 136.8(\mathrm{~s}), 151.6(\mathrm{~s}), 168.4(\mathrm{~s}), 168.8(\mathrm{~s}), 174.1(\mathrm{~s}), 174.5$ (s). Diastereomer 2 (selected signals): ${ }^{1} \mathrm{H}$ NMR $\left(500 \mathrm{MHz}, \mathrm{CDCl}_{3}\right): \delta=1.22(\mathrm{~d}, J 6.3 \mathrm{~Hz}, 3 \mathrm{H}), 1.39(\mathrm{~d}, J 7.3 \mathrm{~Hz}, 3 \mathrm{H}), 1.65(\mathrm{~s}, 3 \mathrm{H}), 7.66$ (bs, $\left.1 \mathrm{H}\right)$. ${ }^{13} \mathrm{C} \mathrm{NMR}\left(125 \mathrm{MHz}, \mathrm{CDCl}_{3}\right): \delta=20.0$ (q), 31.7 (t), 40.9 (t), 46.1 (d), 60.9 (d), 71.6 (d), 116.6 (d), 130.8 (s), 168.5 (s), 169.5 (s), 174.5 (s). HRMS (Cl) calc. for $\mathrm{C}_{25} \mathrm{H}_{35} \mathrm{ClN}_{3} \mathrm{O}_{6}{ }^{+}[\mathrm{M}+\mathrm{H}]^{+}:$508.2209, found 508.2180.

\section{Acknowledgements}

Financial support by the Deutsche Forschungsgemeinschaft (FOR 1406, Ka 880/11-2) is gratefully acknowledged. The authors would also like to thank Jennifer Hermann and Viktoria Schmitt from HelmholtzInstitute for Pharmaceutical Research Saarland (HIPS) for technical assistance with cytotoxicity assays.

\section{Supplementary Material}

General procedures and analytical data of all new compounds.

\section{References}

1. Garcia, R. O.; Krug, D.; Müller, R. Methods Enzymol. 2009, 458, 59-91. https://doi.org/10.1016/S0076-6879(09)04803-4

2. Weissman, K. J.; Müller, R. Nat. Prod. Rep. 2010, 27, 1276-1295. https://doi.org/10.1039/C001260M

3. García-Ruiz, C.; Sarabia, F. Mar. Drugs 2014, 12, 1580-1622. https://doi.org/10.3390/md12031580

4. Dávila-Céspedes, A.; Hufendiek, P.; Crüsemann, M.; Schäberle, T. F.; König, G. M. Beilstein J. Org. Chem. 2016, 12, 969-984. https://doi.org/10.3762/bjoc.12.96

5. Nett, M.; König, G. M. Nat. Prod. Rep. 2007, 24, 1245-1261. https://doi.org/10.1039/b612668p 
6. Wenzel, S. C.; Müller, R. Mol. BioSyst. 2009, 5, 567-574.

https://doi.org/10.1039/B901287G

7. Herrmann, J.; Abou Fayad, A.; Müller, R. Nat. Prod. Rep. 2017, 34, 135-160. https://doi.org/10.1039/C6NP00106H

8. lizuka, R. Fudou, Y. Jojima, S. Ogawa, S. Yamanaka, Y. Inukai, M. Ojika, J. Antibiot. 2006, 59, 385-391. https://doi.org/10.1038/ja.2006.55

9. Ojika, M.; Inukai, Y.; Kito, Y.; Hirata, M.; lizuka, T.; Fudou, R. Chem. Asian J. 2008, 3, 126-133. https://doi.org/10.1002/asia.200700233

10. Kunze, B.; Jansen, R.; Sasse, F.; Höfle, G.; Reichenbach, H. J. Antibiot. 1995, 48, 1262-1266. https://doi.org/10.7164/antibiotics.48.1262

11. Rachid, S.; Krug, D.; Kunze, B.; Kochems, I.; Scharfe, M.; Zabriskie, T. M.; Blöcker, H.; Müller, R. Chem. Biol., 2006, 667-681.

https://doi.org/10.1016/j.chembiol.2006.06.002

12. Herrmann, J.; Hüttel, S.; Müller, R. ChemBioChem, 2013, 14, 1573-1580. https://doi.org/10.1002/cbic.201300140

13. Chan, W. R.; Tinto, W. F.; Manchand, P. S.; Todaro, L. J. J. Org. Chem. 1987, 52, 3091-3093. https://doi.org/10.1021/jo00390a023

14. Tanaka, C.; Tanaka, J.; Bolland, R. F.; Marriott, G.; Higa, T. Tetrahedron 2006, 62, 3536-3542. https://doi.org/10.1016/j.tet.2006.01.099

15. Crews, P.; Manes, L. V.; Boehler, M. Tetrahedron Lett. 1986, 27, 2797-2800. https://doi.org/10.1016/S0040-4039(00)84645-6

16. Zabriskie, T. M.; Klocke, J. A.; Ireland, C. M.; Marcus, A. H.; Molinski, T. F.; Faulkner, J. D.; Xu, C.; Clardy, J. C. J. Am. Chem. Soc. 1986, 108, 3123-3124. https://doi.org/10.1021/ja00271a062

17. Stingl, J.; Andersen, R. J.; Emerman, J. T. Cancer Chemother. Pharmacol. 1992, 30, 401-406. https://doi.org/10.1007/bf00689969

18. Bubb, M. R.; Senderowicz, A. M. J.; Sausville, E. A.; Duncan, K. L. K.; Korn, E. D. J. Biol. Chem. 1994, 269, 14869-14871.

19. Senderowicz, A. M. J.; Kaur, G.; Sainz, E.; Laing, C.; Inman, W. D.; Rodríguez, J.; Crews, P.; Malspeis, L.; Grever, M. R.; Sausville, E. A.; Duncan, K. L. J. Natl. Cancer Inst. 1995, 87, 46-51.

https://doi.org/10.1093/jnci/87.1.46

20. Menhofer, M. H.; Bartel, D.; Liebl, J.; Kubisch, R.; Busse, J.; Wagner, E.; Müller, R.; Vollmar, A. M.; Zahler, S. Cardiovasc Res. 2014, 104, 303-314. https://doi.org/10.1093/cvr/cvu210

21. Menhofer, M. H.; Kubisch, R.; Schreiner, L.; Zorn, M.; Foerster, F.; Müller, R.; Raedler, J.; Wagner, O. E.; Vollmar, A. M.; Zahler, S. PLoS One 2014, 9, e112542. https://doi.org/10.1371/journal.pone.0112542

22. Moser, C.; Rüdiger, D.; Förster, F.; von Blume, J.; Yu, P.; Küster, B.; Kazmaier, U.; Vollmar, A. M.; Zahler, S. Sci. Rep. 2017, 7, 16407. https://doi.org/10.1038/s41598-017-16759-7

23. Gegenfurtner, F. A.; Zisis, T.; Al Danaf, N.; Schrimpf, W.; Kliesmete, Z.; Ziegenhain, C.; Enard, W.; Kazmaier, U.; Lamb, D. C.; Vollmar, A. M.; Zahler, S. Cell Mol Life Sci. 2018, 75, 4539-4555. https://doi.org/10.1007/s00018-018-2919-4 
24. Wang, S.; Crevenna, A. H.; Ugur, I.; Marion, A.; Antes, I.; Kazmaier, U.; Hoyer, M.; Lamb, D.; Gegenfurtner, F.; Kliesmete, Z.; Ziegenhain, C.; Enard, W.; Vollmar, A. M.; Zahler, S. Sci. Rep. 2019, 9, 9731. https://doi.org/10.1038/s41598-019-46282-W

25. Ullrich, A.; Chai, Y.; Pistorius, D.; Elnakady, Y. A.; Herrmann, J. E.; Weissman, K. J.; Kazmaier, U.; Müller, R. Angew. Chem. Int. Ed. 2009, 47, 4422-4425.

https://doi.org/10.1002/anie.200900406

26. Hoffmann, J.; Kazmaier, U. Angew. Chem. Int. Ed. 2014, 53, 11356-11360. https://doi.org/10.1002/anie.201405650

27. Barbie, P.; Kazmaier, U. Org. Lett. 2016, 18, 204-207. https://doi.org/10.1021/acs.orglett.5b03292

28. Gorges, J.; Kazmaier, U. Org. Lett. 2018, 20, 2033-2036. https://doi.org/10.1021/acs.orglett.8b00576

29. Gorges, J.; Kjaerulff, L.; Panter, F.; Hoffmann, T.; Kazmaier, U.; Müller, R. Angew.Chem. Int. Ed. 2018, 57,14270-14275. https://doi.org/10.1002/anie.201808028

30. Junk, L.; Kazmaier, U. Angew. Chem. Int. Ed. 2018, 57, 11432-11435. https://doi.org/10.1002/anie.201806657

31. Becker, D.; Kazmaier, U. Eur. J. Org. Chem. 2015, 2591-2602. https://doi.org/10.1002/ejoc.201403577

32. Becker, D.; Kazmaier, U. Eur. J. Org. Chem. 2015, 4198-4213. https://doi.org/10.1002/ejoc.201500369

33. Karmann, L.; Schulz, K.; Herrmann, J.; Müller, R.; Kazmaier, U. Angew. Chem. Int. Ed. 2015, 54, $4502-4507$. https://doi.org/10.1002/anie.201411212

34. Servatius, P.; Junk, L.; Kazmaier, U. Synlett, 2019, 30, 1289-1302. https://doi.org/10.1055/s-0037-1612417

35. Kappler, S.; Karmann, L.; Prudel, C.; Herrmann, J.; Caddeu, G.; Müller, R.; Vollmar, A. M.; Zahler, S.; Kazmaier, U. Eur. J. Org. Chem. 2018, 6952-6965.

https://doi.org/10.1002/ejoc.201801391

36. Dömling, A. Chem. Rev. 2006, 106, 1, 17-89. https://pubs.acs.org/doi/10.1021/cr0505728

37. Gulevich, A. V.; Zhdanko, A. G.; Orru, R. V. A.; Nenajdenko, V. G. Chem. Rev. 2010, 110, 5235-5331. https://doi.org/10.1021/cr900411f

38. Hebach, C.; Kazmaier, U. J. Chem. Soc. Chem. Commun. 2003, 596-597. https://doi.org/10.1039/B210952B

39. Kazmaier, U.; Hebach, C.; Watzke, A.; Maier, S.; Mues, H.; Huch, V. Org. Biomol. Chem., 2005, 3, $136-145$. https://doi.org/10.1039/B507028G

40. Vercillo, O. E.; Andrade, C. K. Z.; Wessjohann, L. A. Org. Lett. 2008, 10, 2, 205-208. https://doi.org/10.1021/ol702521g

41. Wessjohann, L. A., Rivera, D. G., Vercillo, O. E. Chem. Rev. 2009, 109, 796-814. https://doi.org/10.1021/cr8003407

42. Wessjohann, L. A.; Rhoden, C. R. B.; Rivera, D. G.; Vercillo, O. E. Top Heterocycl. Chem., 2010, 23, $199-226$. https://dx.doi.org/10.1007/7081_2009_25 
43. Ackermann, S.; Lerchen, H.-G.; Häbich, D.; Ullrich, A.; Kazmaier, U. Beilstein J. Org. Chem. 2012, 8, 16521656.

https://doi.org/10.3762/bjoc.8.189

44. Liao, G. P.; Abdelraheem, E. M. M.; Neochoritis C. G.; Kurpiewska, K.; Kalinowska-Tłuścik, J.; McGowan, D. C.; Dömling, A. Org. Lett. 2015, 17, 4980-4983. https://pubs.acs.org/doi/10.1021/acs.orglett.5b02419

45. Madhavachary, R.; Abdelraheem, E. M. M.; Rossetti, A.; Twarda-Clapa, A.; Musielak, B.; Kurpiewska, K.; Kalinowska-Tłuścik, J.; Holak, T. A.; Dömling, A. Angew. Chem. Int. Ed. 2017, 56, 10725-10729. https://doi.org/10.1002/anie.201704426

46. Neises, B.; Steglich, W. Angew. Chem. Int. Ed. Engl. 1978, 17, 522-524. https://doi.org/10.1002/anie.197805221

47. Schmidt, U.; Kroner, M.; Griesser, H. Synthesis 1991, 294-300. https://doi.org/10.1055/s-1991-26448

48. Schmidt, U.; Leitenberger, V.; Griesser, H.; Schmidt, J.; Meyer, R. Synthesis 1992, 1248-1254. https://doi.org/10.1055/s-1992-26351

49. Tanaka, S.; Saburi, H.; Ishibashi, Y.; Kitamura, M. Org. Lett. 2004, 6, 1873-1875. https://doi.org/10.1021/ol0493397 